\title{
Aging-Resilient Associations between the Arcuate Fasciculus and Vocabulary Knowledge: Microstructure or Morphology?
}

\author{
(i) Susan Teubner-Rhodes, ${ }^{1}$ OKenneth I. Vaden Jr., ${ }^{1}$ Stephanie L. Cute, ${ }^{1}$ Jason D. Yeatman, ${ }^{2}$ Robert F. Dougherty, ${ }^{3}$ \\ and Mark A. Eckert ${ }^{1}$ \\ ${ }^{1}$ Department of Otolaryngology-Head and Neck Surgery, Medical University of South Carolina, Charleston, South Carolina 29425-5500, ${ }^{2}$ Institute for \\ Learning and Brain Sciences and Department of Speech and Hearing Sciences, University of Washington, Seattle, Washington 98195-7988, \\ and ${ }^{3}$ Center for Cognitive and Neurobiological Imaging, Stanford University, Stanford, California 94305-2130
}

Vocabulary knowledge is one of the few cognitive functions that is relatively preserved in older adults, but the reasons for this relative preservation have not been well delineated. We tested the hypothesis that individual differences in vocabulary knowledge are influenced by arcuate fasciculus macrostructure (i.e., shape and volume) properties that remain stable during the aging process, rather than white matter microstructure that demonstrates age-related declines. Vocabulary was not associated with age compared to pronounced agerelated declines in cognitive processing speed across 106 healthy adults (19.92-88.29 years) who participated in this neuroimaging experiment. Fractional anisotropy in the left arcuate fasciculus was significantly related to individual variability in vocabulary. This effect was present despite marked age-related differences in a T1-weighted/T2-weighted ratio (T1w/T2w) estimate of myelin that were observed throughout the left arcuate fasciculus and associated with age-related differences in cognitive processing speed. However, atypical patterns of arcuate fasciculus morphology or macrostructure were associated with decreased vocabulary knowledge. These results suggest that deterioration of tissue in the arcuate fasciculus occurs with normal aging, while having limited impact on tract organization that underlies individual differences in the acquisition and retrieval of lexical and semantic information.

Key words: aging; arcuate fasciculus; diffusion tensor imaging; vocabulary; white matter

Significance Statement

Vocabulary knowledge is resilient to widespread age-related declines in brain structure that limit other cognitive functions. We tested the hypothesis that arcuate fasciculus morphology, which supports the development of reading skills that bolster vocabulary, could explain this relative preservation. We disentangled (1) the effects of age-related declines in arcuate microstructure (mean diffusivity; myelin content estimate) that predicted cognitive processing speed but not vocabulary, from (2) relatively stable arcuate macrostructure (shape/volume) that explained significant variance in an age-independent association between fractional anisotropy and vocabulary. This latter result may reflect differences in fiber trajectory and organization that are resilient to aging. We propose that developmental sculpting of the arcuate fasciculus determines acquisition, storage, and access of lexical information across the adult lifespan.

\section{Introduction}

Our ability to retrieve and use word meanings, or vocabulary knowledge, is relatively preserved as we age (Arbuckle et al., 1998;

\footnotetext{
Received Dec. 3, 2015; revised May 19, 2016; accepted May 27, 2016.

Author contributions: S.T.-R., K.I.V., J.D.Y., R.F.D., and M.A.E. designed research; K.I.V., S.L.C., and M.A.E. performed research; S.T.-R., J.D.Y., and M.A.E. analyzed data; S.T.-R., K.I.V., S.L.C., J.D.Y., R.F.D., and M.A.E. wrote the paper.

This work was supported in part by National Institutes of Health/National Institute on Deafness and Other Communication Disorders P50 DC 000422, Medical University of South Carolina Center for Biomedical Imaging, South Carolina Clinical and Translational Research Institute, National Institutes of Health/National Center for Research Resources Grant UL1 RR029882. This investigation was conducted in a facility constructed with support from Research Facilities Improvement Program (C06 RR14516) from the National Center for Research Resources, National Institutes of Health.
}

Park et al., 2002; Schroeder and Salthouse, 2004; Borella et al., 2011) compared with pronounced declines in cognitive processing speed, working memory, and inhibitory control (Salthouse, 1991; Schaie and Willis, 1993; Park et al., 1996, 2002; Persad et al., 2002; Borella et al., 2008, 2011). The relative preservation of vocabulary knowledge is curious when considering evidence that

J.D.Y. has received consulting fees from Invenshure. The remaining authors declare no competing financial interests.

Correspondence should be addressed to either Dr. Susan Teubner-Rhodes or Dr. Mark A. Eckert, Department of Otolaryngology-Head and Neck Surgery, Medical University of South Carolina, 135 Rutledge Avenue, MSC550, Charleston, SC 29425-5500. E-mail: teubnera@musc.edu or eckert@musc.edu.

DOI:10.1523/JNEUROSCI.4342-15.2016

Copyright $\odot 2016$ the authors $\quad 0270-6474 / 16 / 367210-13 \$ 15.00 / 0$ 
age-related structural declines occur within brain regions that support the retrieval and use of word meanings. In particular, the arcuate fasciculus exhibits age-related tissue degeneration (Voineskos et al., 2012), even though the language functions it supports do not show corresponding declines.

The arcuate fasciculus, which connects lateral temporal cortex with ventrolateral frontal cortex, has been linked to varied oral and written language abilities during development. In particular, arcuate fasciculus fractional anisotropy (FA) is predictive of reading skill in children and young adults (Klingberg et al., 2000; Deutsch et al., 2005; Rimrodt et al., 2010; Frye et al., 2011; Hoeft et al., 2011; Yeatman et al., 2011, 2012a, b; Feldman et al., 2012; Vandermosten et al., 2012; Saygin et al., 2013). These observations are important for understanding vocabulary knowledge in older adults because reading abilities early in life affect the growth and attainment of vocabulary (Carlisle, 2000; Lonigan et al., 2009) by increasing exposure to and aiding interpretation of new words (Nagy and Anderson, 1984; Cunningham and Stanovich, 1997). Thus, the arcuate fasciculus is a target for understanding the relative preservation of vocabulary knowledge in older adults.

However, the neural architecture that supports vocabulary knowledge across the lifespan remains unclear. Myelination of the arcuate fasciculus may contribute to differences in FA that predict reading skills (Vandermosten et al., 2012) by influencing the signal conduction (Pajevic et al., 2014) between classic language regions in inferior frontal and lateral temporal cortex. Given that vocabulary shows little decline with age, myelin and other tissue properties should be relatively preserved if critical for the effective access and use of vocabulary knowledge. Alternatively, vocabulary knowledge could be relatively preserved despite age-related declines in white matter tissue if macroanatomical characteristics (i.e., shape and volume) of the arcuate are critical for demonstrating vocabulary knowledge, especially for tasks requiring lexical access rather than speed. This macrostructural hypothesis is consistent with evidence that fiber tract projection patterns map to functional organization within participants (Saygin et al., 2012; Hermundstad et al., 2013; Osher et al., 2016).

In the present study, we used a multimodal imaging approach to investigate why vocabulary knowledge is relatively preserved across the adult lifespan. This approach helped disentangle the effects of aging and normal individual differences on measures of tract microstructure that predict vocabulary, as these metrics can reflect multiple structural features, including myelin, tissue density, axon density, and axonal coherence (Beaulieu, 2002; Mädler et al., 2008; Schmierer et al., 2008). Specifically, we first examined the degree to which FA and mean diffusivity (MD) in the arcuate fasciculus were uniquely related to vocabulary (Feldman et al., 2012) versus cognitive processing speed, a function that reliably declines with age (Kennedy and Raz, 2009; Eckert, 2011; Fjell et al., 2012). We then examined the extent to which macrostructural organization versus microstructural declines explained these patterns of association. Macrostructural organization was defined using an arcuate fasciculus volume measure that was sensitive to tract shape and independent of age. Age-related microstructural declines were assessed using a T1-weighted/T2-weighted ratio (T1w/T2w) metric that has been shown to be sensitive to the concentration of myelin (Glasser and Van Essen, 2011; Ganzetti et al., 2014; Glasser et al., 2014). These analyses were performed in the same space of the arcuate fasciculus to (1) show that normal individual differences and aging effects can differentially affect white matter metrics, and (2) explain why vocabulary knowledge can be relatively preserved despite evidence of age-related declines in supporting neural architecture.

\section{Materials and Methods}

\section{Participants}

A total of 106 adults (age: mean 54.67 years, range 19.92-88.29 years; education: mean 15.75 years, range 11-20 years) participated in this study. The largely right-handed sample (Edinburgh handedness: mean 70.38 , range -100 to 100 ) included 60 female participants. An additional 2 participants (a 70.55-year-old man and a 46.65-year-old man) completed the study but were excluded from all analyses because of image reconstruction errors.

Participants were recruited for a study on age-related hearing loss and contributed to the collection of data that included structural MRI and cognitive ability data, in addition to measures of language and hearing. Exclusionary criteria for participating in this neuroimaging study included a history of head trauma, seizures, self-reported CNS disorders, conductive hearing loss or otologic disease, and contraindications for safe MRI scanning. Participants provided written informed consent before participating in this Medical University of South Carolina Institutional Review Board-approved study. All procedures performed were in accordance with the ethical standards of the institutional and/or national research committee and with the 1964 Helsinki declaration and its later amendments or comparable ethical standards.

\section{Cognitive assessments}

The cognitive assessment battery included subtests from the Wechsler Abbreviated Scale of Intelligence (WASI) (Wechsler, 1999), WoodcockJohnson III (WJ-III) Tests of Cognitive Ability and Tests of Achievement (Woodcock et al., 2001), and the Connections cognitive processing speed test (Salthouse et al., 2000). Subtests from these assessments were selected to evaluate the associations of vocabulary and processing speed with arcuate fasciculus microstructure.

The WASI test of Vocabulary Knowledge served as the primary measure of vocabulary. For this task, participants defined vocabulary words from a set of 40 items presented both verbally and in written form by identifying their main category, features, or functions, or by giving a specific example of the word. Participants earned between 0 and 2 points on each item based on the quality of their response for up to 80 points in total. This task assesses expressive vocabulary skills and was selected because it taps both the breadth and depth of semantic knowledge.

The WJ-III Picture Vocabulary test served as a secondary measure of vocabulary to verify results obtained with the WASI test of Vocabulary Knowledge. This task required participants to orally identify up to 44 pictured nouns, with the difficulty of the starting item determined by age and education. Testing proceeded to easier or harder items depending on performance until the participant made 6 consecutive correct or incorrect responses, respectively. Each correct response was worth 1 point, with possible scores ranging from 0 to 44 . This task assesses object recognition, expressive vocabulary, and word retrieval.

Finally, the Connections Simple test served as a measure of processing speed. For this task, participants connected circles containing either numbers or letters in numerical or alphabetical order, respectively. Participants were given $20 \mathrm{~s}$ to connect as many circles of 48 as possible. The numbers and letters tests were each administered twice, and the mean number of connections across the four assessments was used as the Connections Simple score. Higher scores (i.e., more connections) indicate faster processing speed.

Raw scores on the cognitive tests were converted to $Z$-scores for all analyses. One participant whose score fell $>3$ SDs below the mean was excluded from the analyses for WASI Vocabulary Knowledge, so that outliers would not impact the individual difference analyses.

\section{MRI data acquisition}

A Siemens 3 T Tim Trio and 32 channel head coil were used to collect T1-weighted, fluid-attenuated inversion recovery (FLAIR) T2-weighted, and diffusion images. The T1-weighted images were collected using a 3D MPRAGE acquisition sequence (Mugler and Brookeman, 1990) with the following parameters: $6.28 \mathrm{~min}$ scan, 160 slices, sagittal plane, $256 \times 256$ matrix, $\mathrm{TR}=2250 \mathrm{~ms}, \mathrm{TE}=4.15 \mathrm{~ms}$, flip angle $=9^{\circ}, \mathrm{TI}=900 \mathrm{~ms}$; slice thickness $=1 \mathrm{~mm}$, no slice gap, and an in-plane resolution $=1.0 \times 1.0$ $\mathrm{mm}$. The following parameters were used to acquire 2D FLAIR T2- 
weighted images: 3.93 min scan, 42 slices, axial plane, $384 \times 384$ matrix, $\mathrm{TR}=9000 \mathrm{~ms}$, $\mathrm{TI}=2500 \mathrm{~ms}$, $\mathrm{TE}=94 \mathrm{~ms}$, flip angle $=180^{\circ}$, slice thickness $=3 \mathrm{~mm}$, no slice gap, and an in-plane resolution $=0.5 \times 0.5$ $\mathrm{mm}$. The diffusion images were collected using a $2 \mathrm{D}$ single-echo EPI acquisition sequence with the following parameters: 9.10 min scan, inplane GRAPPA acceleration factor $=2,64$ diffusion directions at $\mathrm{b}=$ $1000,1 \mathrm{~b}=0$ image, sagittal plane, $\mathrm{TE}=88 \mathrm{~ms}, \mathrm{TR}=8000 \mathrm{~ms}$, flip angle $=90^{\circ}, \mathrm{FOV}=208 \mathrm{~mm}$, image dimensions $=104 \times 104 \times 64$, and $2 \mathrm{~mm}$ thick slices (resulting in $2 \mathrm{~mm}^{3}$ isomorphic voxels).

Diffusion image processing. Affine eddy-current correction and tensor fitting of the diffusion data were performed using the FMRIB Diffusion Toolbox (Behrens et al., 2003). The resulting diffusion images from each participant were coregistered to their native space T1 image using the SPM8 mutual information algorithm and then saved with the T1 image in a MATLAB MAT-file with the coregistration information to be read by mrDiffusion software (www.vistalab.stanford.edu). Deterministic whole-brain streamline tractography was then performed using the default algorithm in Automated Fiber Quantification (AFQ) (Yeatman et al., 2012b). Trilinear interpolation of the tensor data was used to estimate a continuous tensor field across the brain. Streamline tracking was conducted using a fourth-order Runge-Kutta path integration method (Basser et al., 2000) and $1 \mathrm{~mm}$ fixed-step size. Whole-brain fiber tracking was initialized from seed points within a white matter mask containing all voxels where FA was $>0.3$ and proceeded in both directions along the principal diffusion axis. Tracking stopped when the fiber angle changed $>30^{\circ}$ or FA was $<0.2$. Only fibers with lengths between 50 and $250 \mathrm{~mm}$ were retained to avoid including spurious fibers that were too short or too long. This approach generated a set of whole-brain fibers that could then be parcellated to identify fiber tracts of interest.

Fiber tracts were identified from the set of whole-brain streamline fibers by selecting the fibers that pass through two way-point regions of interest (ROIs) defining the trajectory of each tract (Yeatman et al., 2012b). Two branches of the superior longitudinal fasciculus (SLF) were examined: (1) the arcuate fasciculus segment that projects directly between frontal and temporal cortex; and (2) the frontoparietal or anterior segment of the SLF (Catani et al., 2005). The anterior ROI for both branches was a $2 \mathrm{D}$ coronal plane that was placed at the central sulcus and spanned the extent of frontal white matter (excluding the cingulum). For the arcuate fasciculus, the posterior ROI was a $2 \mathrm{D}$ axial plane that was placed in the temporal lobe. It extended posterior to anterior from the preoccipital notch through the superior temporal sulcus to Heschl's sulcus. The posterior ROI for the frontoparietal branch of the SLF was a coronal plane placed at the posterior boundary of the splenium. ROIs were defined in MNI space using the Mori Atlas (Mori et al., 2008) that is packaged with AFQ. These ROIs were transformed from normalized space into the native space of each participant's diffusion data to ensure that the same ROI was used and placed in a consistent location across participants. Too few fibers were identified to obtain reliable diffusion estimates for left arcuate fasciculus tracts in 3 participants and right arcuate fasciculus tracts in 20 participants. This observation is consistent with previous studies showing that the arcuate fasciculus is more consistently tracked across participants in the left than the right hemisphere using these methods (Yeatman et al., 2011; Johnson et al., 2013). The left and right frontoparietal branch of the SLF was identified in all participants.

Core-weighted diffusion metrics (FA and MD) were calculated for 100 evenly spaced positions (i.e., nodes) along the center of each participant's native space tracts between the two ROIs. This approach normalized the distance along each native-space tract so that Pearson correlations could be performed across participants (Yeatman et al., 2011; Wandell and Yeatman, 2013). AFQ was also used to exclude spurious fibers that projected $>20 \mathrm{~mm}$ beyond an ROI or from the core of the tract.

T1w/T2w processing. Myelin-enhanced contrast images were computed based on a T1w/T2w image (Glasser and Van Essen, 2011). T2weighted data (i.e., FLAIR) were not obtained for two participants who were thus excluded from this analysis. All preprocessing of T1-weighted and T2-weighted images was conducted in SPM8. Images in native space were first bias-corrected using regularization of .0001 and a FWHM Gaussian smoothing cutoff of $60 \mathrm{~mm}$ to minimize differences in $\mathrm{T} 1$ and
T2 image transmit field biases before computing the ratio (Ganzetti et al., 2014). The T2 image was then coregistered to the T1 image using normalized mutual information and resliced with trilinear interpolation. These images were segmented using the SPM8 unified segmentation algorithm, which applies a nonlinear deformation field to ICBM Tissue Probabilistic Atlases to match native space images (Ashburner and Friston, 2005). This generated T1 and T2 image-specific gray-matter probability masks. The mean gray-matter value from voxels with a gray-matter probability $>0.5$ was extracted from the gray-matter mask for each $\mathrm{T} 1$ and T2 image and used for subsequent normalization of voxel intensity. Intensity normalization was necessary to obtain a common scale of voxel values to produce a $\mathrm{T} 1 \mathrm{w} / \mathrm{T} 2 \mathrm{w}$ ratio image. The intensity was normalized separately for each T1 and T2 image (Glasser and Van Essen, 2011; Ganzetti et al., 2014) by removing values that were $>3$ SDs beyond the mean intensity of the bias-corrected image and dividing by the corresponding mean gray-matter value. Finally, the normalized and bias-corrected T1weighted image was divided by the normalized and bias-corrected T2weighted image to yield a T1w/T2w image in native space for each participant. Because the T1-weighted image was aligned to the diffusion data, we were able to compute core-weighted averages of T1w/T2w at each of the 100 AFQ tract nodes of the arcuate fasciculus.

Local tract volume processing. Arcuate fasciculus morphology was computed as the local volume of the tract at each of the 100 nodes. Volume was calculated specifically across AFQ nodes where there were permutation-corrected significant associations between diffusion metrics and vocabulary. Two different automated methods were used to compute local tract volume. The first method counted the number of unique voxels that the fibers intersected at each node to estimate tract volume in cubic millimeters. The second method estimated tract volume by fitting an ellipsoid, or covariance matrix, to model the tract shape at each node, and computing the ellipsoid volume in cubic millimeters. These variables were strongly related $(r=0.77, p<0.001)$, indicating similar sensitivity to tract volume. Arcuate fasciculus volume was classified as atypical for participants whose volume estimates were $1 \mathrm{SD}$ above (high volume) or below (low volume) the mean tract volume across participants for both methods. Using both volume metrics ensured reliable estimation of atypical volume, as the main difference between the two methods is how they are affected by fiber outliers that deviate substantially from the tract core. The combined classification measure also reflects atypical shape because it will be influenced by the local angle and spread of fibers. Specifically, unusually extensive flaring of fibers or unusually widespread projections in the ROI can result in high volume whereas unusually limited spread can result in low volume. To assess how brain size affected local tract volume, we also computed intracranial volume for each subject by summing native space gray matter, white matter, and CSF probabilities from SPM8 segmented images.

\section{Combining multiple measurements to dissociate different tissue properties}

Diffusivity metrics can be regionally independent because of differential sensitivities to fiber tract properties (Burzynska et al., 2010). Although decreased FA and increased MD often co-occur in older adults (Lebel et al., 2012), using multiple metrics can help to uniquely characterize the biological structure that is affected by aging (Yeatman et al., 2014). However, determining the precise tissue properties that underlie individual differences in FA and MD is not straightforward. These measures fundamentally reflect local restrictions on the rate (MD) and direction (FA) of diffusion, so several different combinations of structural features could give rise to identical values of these metrics (Bennett et al., 2010; Jones et al., 2013). Thus, T1w/T2w and local tract volume measures were used to better understand specific tissue properties that might contribute to any observed diffusion effects. Below, we define the tissue properties that were characterized with each metric.

$F A$. The extent to which diffusion is anisotropic (i.e., directional) in neural tissue depends on both intra- and extra-axonal barriers to diffusion. Increased number and density of microtubules and neurofilaments and decreased membrane permeability can all increase diffusion in the parallel relative to the perpendicular direction within the axon (Beaulieu, 2002; Mädler et al., 2008). Outside of the axon, the number, packing 
density, and degree of orientation coherence of axons, the thickness of the myelin sheath, and the presence of crossing fibers can all affect anisotropy (Beaulieu, 2002; Mädler et al., 2008; Jones et al., 2013). Although FA is often used to index myelin integrity, axons with high directional coherence can exhibit high FA despite having low myelin content (Beaulieu, 2002; Mädler et al., 2008). Thus, differences in FA are only presumed to reflect differences in myelination when FA corresponds to other myelin indices, such as T1w/T2w. In regions where FA is not related to $\mathrm{T} 1 \mathrm{w} / \mathrm{T} 2 \mathrm{w}$, differences are more likely to reflect the organizational coherence of fibers, which may be observable in morphological measures, such as local tract volume. FA can be further characterized by examining axial diffusivity $(\mathrm{AD})$ and radial diffusivity $(\mathrm{RD})$, which reflect diffusion parallel and perpendicular to the principal diffusion direction, respectively. These measures have been used to determine the source of significant FA associations, where a pattern of high $\mathrm{FA}$ and $\mathrm{AD}$ and low $\mathrm{RD}$ in white matter is thought to indicate tightly bundled, coherently organized axons (Frye et al., 2011; Yeatman et al., 2011; Vandermosten et al., 2012).

MD. MD and FA often covary because features, such as axon size, membrane density, and myelination, inversely affect these measures (Lebel et al., 2012). However, widespread age-related increases in MD are observed in frontal and temporal white matter in the absence of corresponding changes in FA (Zhang et al., 2010), suggesting that MD may be more sensitive to tissue degeneration in normal aging. This dissociation may occur in regions where FA is primarily driven by the degree of coherence of axonal orientation (Beaulieu, 2002; Mädler et al., 2008; Zhang et al., 2010) and so is less affected by white matter damage or loss. Thus, T1w/T2w should covary with MD, but not FA, in regions of crossing and branching fibers.

T1w/T2w. Dividing T1 by T2 enhances the contrast for white matter by correcting for scanner biases and improving the signal-to-noise ratio (Glasser and Van Essen, 2011). As the byproduct of two nonquantitative images, T1w/T2w is not a specific measure of myelin. However, it appears to capture known differences in myelin density across neuronal structures and corresponds with other metrics thought to reflect myelin, including FA and the magnetization transfer ratio (Ganzetti et al., 2014). Additionally, T1w/T2w exhibits an inverted U-shaped aging pattern across $\sim 90 \%$ of the cortical ribbon, paralleling the canonical trajectory of cortical myelin across the lifespan (Grydeland et al., 2013). These findings suggest that $\mathrm{T} 1 \mathrm{w} / \mathrm{T} 2 \mathrm{w}$ is a sensitive, although perhaps not specific, marker of myelin and can index age-related declines in microstructure.

Local tract volume. The volume of a given streamline-derived tract region is a product of the total number of fibers, axon size, and the complexity and spread of local fiber trajectories (Frye et al., 2011; Lebel et al., 2012; Ocklenburg et al., 2014). Relatively limited loss of tract volume occurs with age compared with pronounced declines in metrics of microstructure (Sala et al., 2012). Thus, tract volume provides a relatively stable index of developmental differences in morphology and organization.

Like measures of microstructure, tract volume is a complex metric of the underlying tissue structure. Low tract volume can co-occur with low FA, possibly reflecting a small number of fibers (Ocklenburg et al., 2014), but high tract volume can also occur with low FA when fibers spread out due to widespread terminations or the presence of crossing fibers (Frye et al., 2011). Thus, both low and high tract volume can reveal atypical tract organization across individuals.

\section{Statistical analyses}

Correlation analyses between demographic variables (age and education) and cognitive variables (Vocabulary Knowledge, Picture Vocabulary, and Connections Simple) were performed in SPSS (IBM, 2013) to understand individual differences in performance on the cognitive tasks. Correlations with a quadratic term for age $\left(\right.$ age $\left.^{2}\right)$, which consisted of the residuals of age-squared after regressing out age in years (see, e.g., Park et al., 1996), were also computed to investigate the possibility of U-shaped aging effects on performance.

Correlation analyses between the core-weighted diffusion metrics (FA and MD) and the primary cognitive variables of interest, Vocabulary Knowledge and Connections Simple, were performed in $\mathrm{R}$ (version 2.15.0). Correlations were performed at each of 100 nodes in the left and right arcuate fasciculus. Results were corrected for multiple comparisons
Table 1. Correlations of education and age with vocabulary and processing speed measures $^{a}$

\begin{tabular}{|c|c|c|c|}
\hline & $\begin{array}{l}\text { Vocabulary } \\
\text { Knowledge }\end{array}$ & $\begin{array}{l}\text { Picture } \\
\text { Vocabulary }\end{array}$ & $\begin{array}{l}\text { Connections } \\
\text { Simple }\end{array}$ \\
\hline \multicolumn{4}{|c|}{ Simple correlations } \\
\hline Education & $0.54^{* * *}$ & $0.45^{* * *}$ & 0.05 \\
\hline Age & 0.04 & 0.16 & $-0.64 * * *$ \\
\hline $\mathrm{Age}^{2}$ & 0.10 & 0.02 & 0.02 \\
\hline \multicolumn{4}{|c|}{ Partial correlations controlling for education } \\
\hline Education & - & - & - \\
\hline Age & 0.05 & 0.18 & $-0.64^{* * *}$ \\
\hline $\mathrm{Age}^{2}$ & -0.03 & -0.10 & 0.00 \\
\hline
\end{tabular}

${ }^{a}$ Simple correlations with Z-transformed scores on the cognitive metrics and partial correlations after controlling for education. Age ${ }^{2}$, Residuals of age-squared after regressing out actual age in years. Bootstrap (1000) Cls for significant correlations: Education with Vocabulary Knowledge [0.39, 0.67], Picture Vocabulary [0.27, 0.59]; Age with Connections Simple $[-0.75,-0.53]$.

*** $p<0.001$.

using nonparametric random permutation tests because statistical results in neighboring tract positions are nonindependent (10,000 permutations; family-wise error corrected $\alpha=0.05$ ) (Nichols and Holmes, 2002). Follow-up uncorrected control analyses were performed for positive permutation results to better characterize the primary FA and MD effects. For each result, the longest contiguous distribution of nodes where diffusion metrics significantly correlated with vocabulary or processing speed was used to compute a mean FA or MD metric for follow-up behavioral and diffusion control analyses. These control analyses (1) determined the specificity of observed associations between diffusion metrics and performance, (2) assessed the degree to which these associations were dependent on age and associated declines in $\mathrm{T} 1 \mathrm{w} / \mathrm{T} 2 \mathrm{w}$, and (3) controlled for demographic variables and total intracranial volume.

\section{Results}

\section{Education and age associations with cognitive measures}

Table 1 shows that vocabulary, but not processing speed, was higher for individuals who had more education, whereas processing speed, but not vocabulary, declined with age (Fig. 1). These results are consistent with prior evidence showing that processing speed exhibits greater aging-related decrements than declarative knowledge like vocabulary (Schaie and Willis, 1993; Park et al., 2002). The absence of a relationship between age and vocabulary could not be attributed to cross-sectional differences in years of education or to a U-shaped aging pattern. No significant correlations between age and vocabulary emerged after controlling for education (Table 1, bottom half).

To ensure that including both left- and right-handed participants in our sample did not affect the results, participants were categorized by Edinburgh handedness into left $(-100$ to $0 ; n=$ $14)$, right $(1-74 ; n=14)$, and strongly right-handed $(75-100 ; n=$ 78 ) groups due to a rightward skewed distribution. Handedness groups did not exhibit significant mean differences in performance on any of the cognitive assessments (Vocabulary Knowledge: $F_{(2,102)}=2.22, p=0.11$; Picture Vocabulary: $F_{(2,103)}=1.92$, $p=0.15$; Connections Simple: $\left.F_{(2,103)}=1.10, p=0.34\right)$, nor $\mathrm{did}$ the relationship between age and performance on the cognitive assessments differ between the handedness groups (Vocabulary Knowledge: $Z s<1.10$, ps $>0.27$; Picture Vocabulary: $Z s<1.53$, ps $>0.13$; Connections Simple: $Z s<0.81$, ps $>0.42$ ).

\section{Arcuate FA selectively predicts vocabulary knowledge}

Significant positive correlations were observed between left arcuate fasciculus FA and Vocabulary Knowledge where the tract descends toward the temporal lobe behind the posterior end of the Sylvian fissure (Figs. 2, 3A) (nodes 73-88, FA: $r s=[0.30,0.39]$, 
A

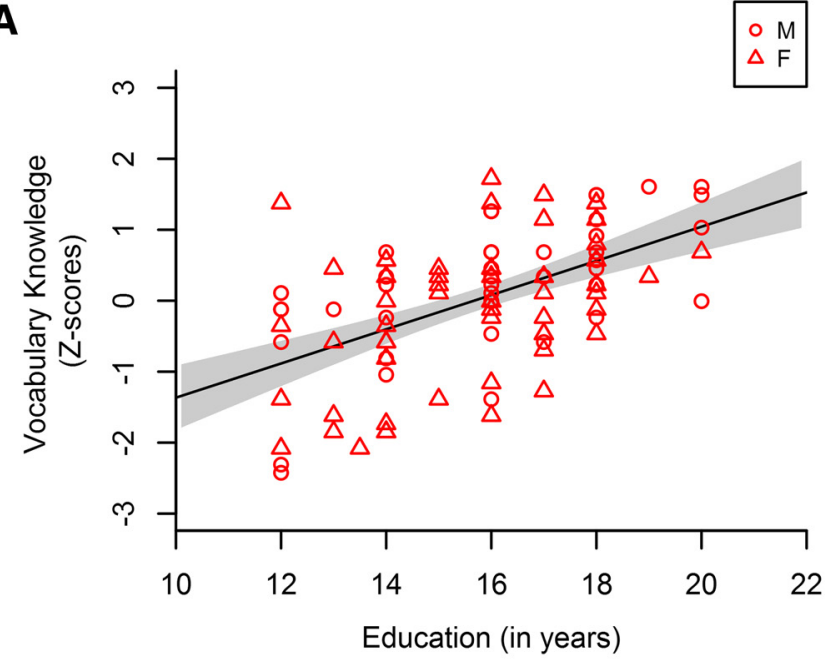

C

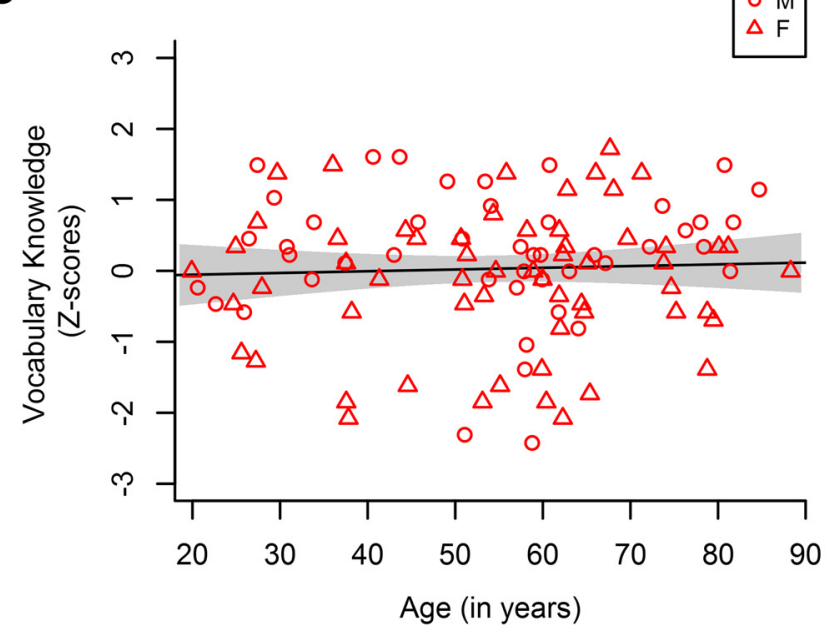

B
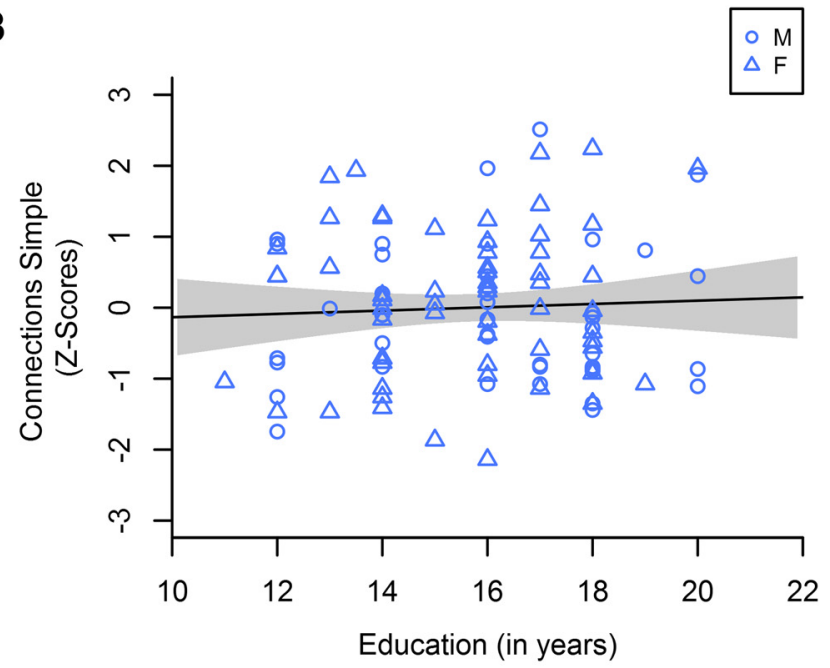

D

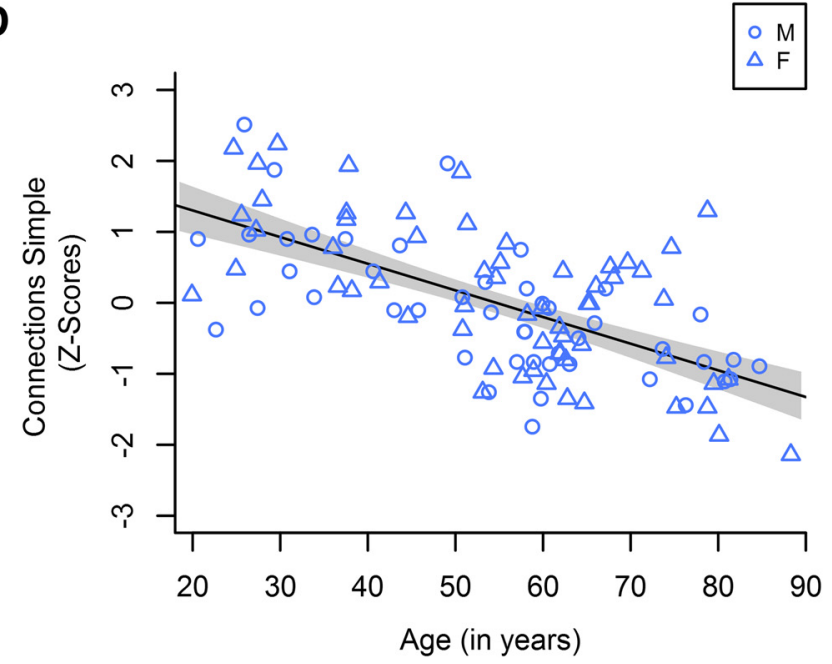

Figure 1. Correlations of education (top) and age (bottom) with vocabulary (red, left) and processing speed (blue, right). M, Male; $\mathrm{F}$, female. Gray shading represents the $95 \%$ Cl. Processing speed was measured by performance on the Connections Simple task such that higher values indicate faster processing speed. $\boldsymbol{A}, \boldsymbol{B}$, Education was significantly positively correlated with Vocabulary Knowledge but not processing speed. C, D, Age in years did not predict Vocabulary Knowledge but was significantly negatively correlated with processing speed.

$\left.p \mathrm{~s}_{\mathrm{FWE}}<0.05 ; \mathrm{MD}: p \mathrm{~s}_{\mathrm{FWE}}>0.10\right)$. Weaker associations that did not survive correction for multiple comparisons were observed for FA in the right arcuate fasciculus (nodes 81-94, $r \mathrm{~s}=[0.21$, 0.29 ], ps $<0.05$ uncorrected). By contrast, Vocabulary Knowledge was not related to diffusion metrics in the frontoparietal branch of the SLF within the left (FA: $p s_{\mathrm{FWE}}>0.12 ; \mathrm{MD}: p \mathrm{~s}_{\mathrm{FWE}}>$ 0.26 ) or right hemisphere (FA: $p s_{\mathrm{FWE}}>0.16$; MD: $p s_{\mathrm{FWE}}>0.86$ ).

A follow-up multiple regression analysis on nodes 73-88 of the left arcuate fasciculus demonstrated that $\mathrm{RD}$, but not $\mathrm{AD}$, was a significant predictor of Vocabulary Knowledge (RD: $\beta=$ $-0.34, t_{(99)}=-3.41, p<0.001 ; \mathrm{AD}: \beta=0.08, t_{(99)}=0.82, p=$ 0.41 ; all reported $\beta$ values are standard estimates), suggesting that the FA-Vocabulary Knowledge relationship was primarily driven by diffusivity perpendicular to the principal diffusion direction. FA in this region was also associated with Picture Vocabulary but not with Connections Simple performance (Table 2), suggesting that this result was specific to word knowledge.

Despite males having higher vocabulary scores than females (Vocabulary Knowledge: $t_{(103)}=2.08, p<0.05$; Picture Vocabulary: $\left.t_{(104)}=3.48, p<0.001\right)$, correlations between left arcuate fasciculus FA and vocabulary did not significantly differ by gender (Vocabulary Knowledge: $Z=-0.54, p=0.59$; Picture Vocabulary: $Z=-0.16, p=0.88)$. Similarly, there was no significant difference in the strength of this relation between handedness groups (Vocabulary Knowledge: $Z s<1.46$, ps $>$ 0.14; Picture Vocabulary: $Z s<0.99$, ps $>0.32$ ).

\section{Arcuate fasciculus diffusivity selectively predicts processing speed}

Processing speed was not significantly predicted by arcuate fasciculus FA (left: $p s_{\mathrm{FWE}}>0.26$; right: $p \mathrm{~s}_{\mathrm{FWE}}>0.43$ ). However, $\mathrm{MD}$ in the left arcuate fasciculus was significantly negatively correlated with processing speed in a large segment of the tract that overlaps with the region that was associated with Vocabulary Knowledge (Fig. 3B; nodes $9-11$ and 40-85: $r s=[-0.28$, $\left.-0.40], p s_{\mathrm{FWE}}<0.05\right)$. MD along a similar segment of the right arcuate fasciculus was also significantly negatively correlated with processing speed (Fig. 3C; nodes $51-75$ and 79-80, $r$ s $=[-0.31$, $\left.-0.41], p s_{\mathrm{FWE}}<0.05\right)$. Significant negative correlations between $\mathrm{MD}$ and processing speed were also observed in anterior and posterior segments of the left frontoparietal SLF (nodes 1-11 and $\left.94-100, r s=[-0.26,-0.30], p s_{\mathrm{FWE}}<0.05\right)$ and a posterior segment of the right frontoparietal SLF (nodes 84-100, $r$ s $=$ $\left.[-0.26,-0.33], p \mathrm{~s}_{\mathrm{FWE}}<0.05\right)$. None of the correlations between FA and processing speed in the frontoparietal SLF were significant (left: $p s_{\mathrm{FWE}}>0.14$; right: $p \mathrm{~s}_{\mathrm{FWE}}>0.09$ ). 


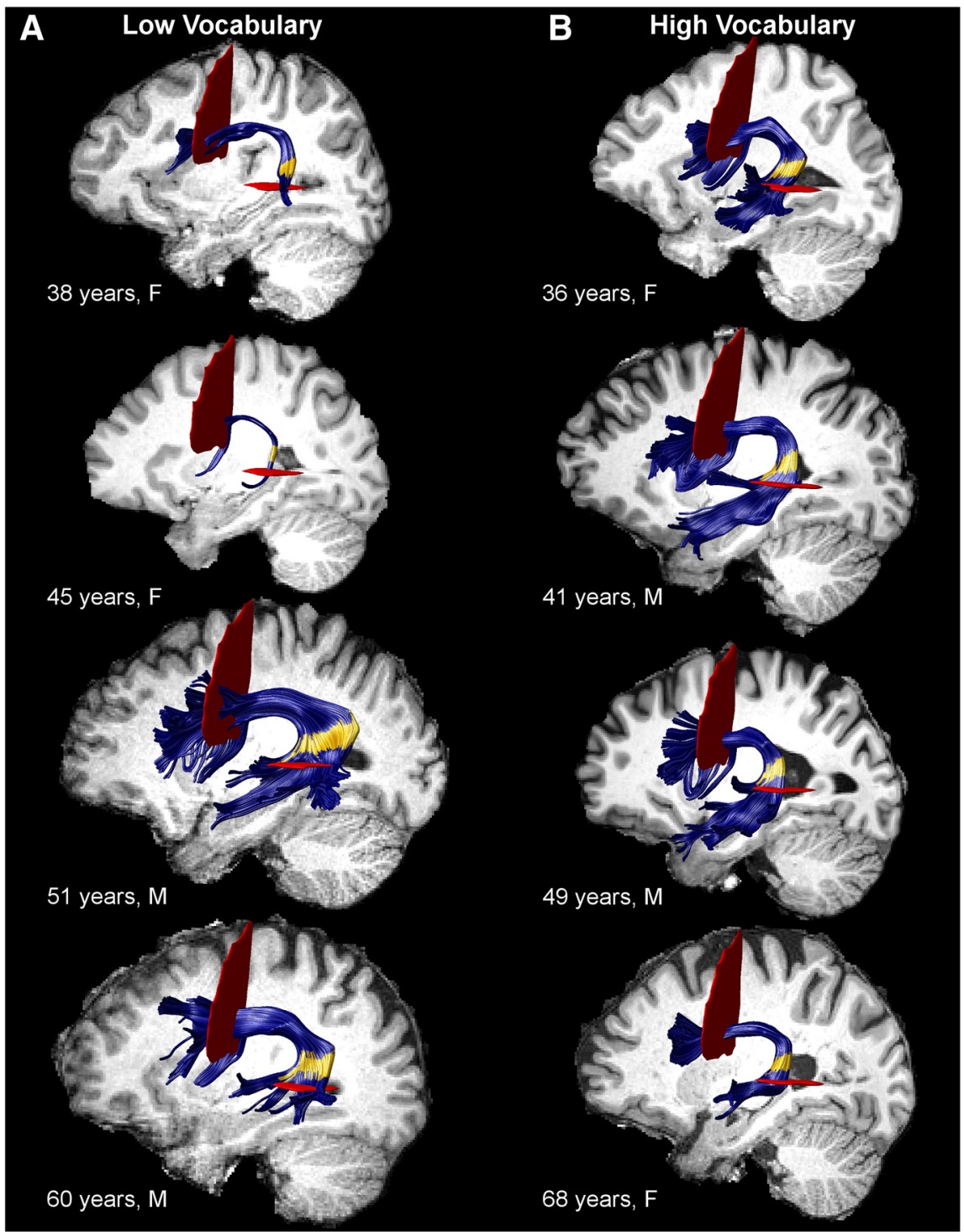

Figure 2. Tract renderings of the left arcuate fasciculus from selected participants with $(\boldsymbol{A})$ low Vocabulary Knowledge (bottom quartile) and low or high tract volume and $(\boldsymbol{B})$ high Vocabulary Knowledge (top quartile) and normal tract volume. F, Female; $M$ male. Yellow area in the posterior segment of the tract represents nodes 73-88 where FA was significantly positively correlated with Vocabulary Knowledge ( $p_{\mathrm{FWE}}<0.05$ ). Some fibers do not appear to pass through the ROls for individual participants; this is because AFQ's fiber selection algorithm uses a smoothed ROI to correct for small errors in coregistration from MNI space to the participant's native space.

As shown in Table 2 and Figure 4, the FA-Vocabulary Knowledge and MD-processing speed associations in the arcuate fasciculus were statistically unique effects (i.e., cases with high MD and low processing speed did not have low FA and low Vocabulary Knowledge). Together with the FA and vocabulary results, these findings demonstrate unique influences on cognition within overlapping regions of the arcuate fasciculus.

White matter associations with vocabulary knowledge are age-independent

T1w/T2w proved to be a sensitive index of age-related tissue declines. As shown in Table 3, age was significantly and negatively correlated with T1w/T2w in nodes 73-88 of the left arcuate fasciculus, where FA was associated with vocabulary (Fig. $5 A$ ). This region of the arcuate fasciculus was therefore susceptible to agerelated differences in white matter microstructure. FA was not, however, significantly correlated with age or T1w/T2w (Table 3;
Fig. 5). In particular, hierarchical regression showed that, although FA was a significant predictor of Vocabulary Knowledge $\left(\beta=0.38, t_{(98)}=4.10, p<0.001\right)$, neither age nor T1w/T2 $\mathrm{w}$ significantly improved model fit (age: $\Delta R^{2}=0.001, F_{(1,97)}$ $=0.07, p=0.80 ; \mathrm{T} 1 \mathrm{w} / \mathrm{T} 2 \mathrm{w}: \Delta R^{2}<0.001$, $\left.F_{(1,97)}=0.001, p=0.98\right)$ and including them in the model did not diminish the strength of FA as a predictor $(\beta=0.38$, $\left.t_{(96)}=4.03, p<0.001\right)$. These results indicate that the relationship between left arcuate fasciculus FA and vocabulary persisted across the lifespan despite agerelated differences in tract microstructure, which may be due to declining myelin.

\section{White matter associations with} processing speed are age-dependent Compared with the FA and vocabulary results, regions where MD was associated with processing speed showed a different pattern of association with age and T1w/T2w. MD was significantly correlated with age (positively) and T1w/T2w (negatively) in the left and right arcuate fasciculus as well as the left and right frontoparietal SLF (Table 3; Fig. 5). These results suggest that age-related white matter decline occurred where there were age-related increases in $\mathrm{MD}$, as expected when barriers to diffusion are reduced.

Hierarchical regression demonstrated that age predicted processing speed above and beyond $\mathrm{MD}$ in the arcuate fasciculus (left, nodes 40-85: $\beta=-0.57, t_{(98)}=$ $-7.00, p<0.001$; right, nodes $51-75: \beta=$ $\left.-0.56, t_{(81)}=-6.60, p<0.001\right)$ and the frontoparietal SLF (left, nodes 1-11: $\beta=$ $-0.61, t_{(101)}=-7.74, p<0.001$; right, nodes $84-100: \beta=-0.60, t_{(101)}=-7.71$, $p<0.001)$. Adding age to the model reduced the strength of MD as a predictor of processing speed in all regions of interest (left arcuate, nodes 40-85: from $\beta=$ -0.41 to $\beta=-0.19, t_{(98)}=-2.37, p=0.02$; right arcuate, nodes $51-75$ : from $\beta=-0.44$ to $\beta=-0.26, t_{(81)}=-3.08, p<0.01$; left frontoparietal SLF, nodes $1-11$ : from $\beta=-0.28$ to $\beta=-0.10$, $t_{(101)}=-1.20, p=0.23$; right frontoparietal SLF, nodes 84-100: from $\beta=-0.31$ to $\left.\beta=-0.14, t_{(101)}=-1.82, p=0.07\right)$. Adding T1w/T2w did not further improve model fit for the arcuate fasciculus (left, nodes 40-85: $\Delta R^{2}=0.004, F_{(1,97)}=0.67, p=0.43$; right, nodes 51-75: $\Delta R^{2}=0.004, F_{(1,80)}=0.61, p=0.44$; collinearity diagnostics indicated that $42 \%-50 \%$ of the variance in the T1w/T2w ratio was explained by age and MD in the left and right arcuate) or the frontoparietal SLF (left, nodes 1-11: $\Delta R^{2}=$ $0.0004, F_{(1,100)}=0.07, p=0.80$; right, nodes $84-100: \Delta R^{2}=$ $0.02, F_{(1,100)}=2.78, p=0.10$; collinearity diagnostics indicated that $52 \%-57 \%$ of the variance in the $\mathrm{T} 1 \mathrm{w} / \mathrm{T} 2 \mathrm{w}$ ratio was explained by age and MD in the left and right frontoparietal SLF), but replacing age with $\mathrm{T} 1 \mathrm{w} / \mathrm{T} 2 \mathrm{w}$ yielded a similar pattern of results. Thus, age-related declines in tract microstructure contrib- 


\section{A Left Arcuate FA and Vocabulary Knowledge}
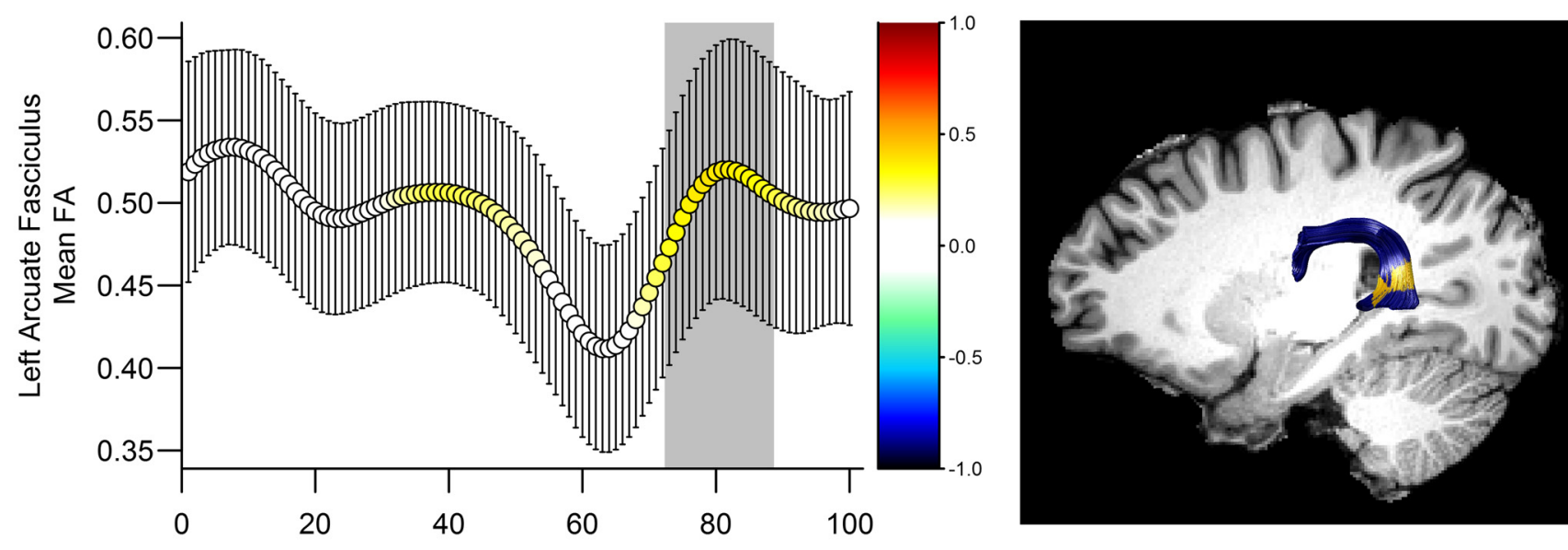

Node Position (anterior to posterior)

\section{B Left Arcuate MD and Processing Speed}
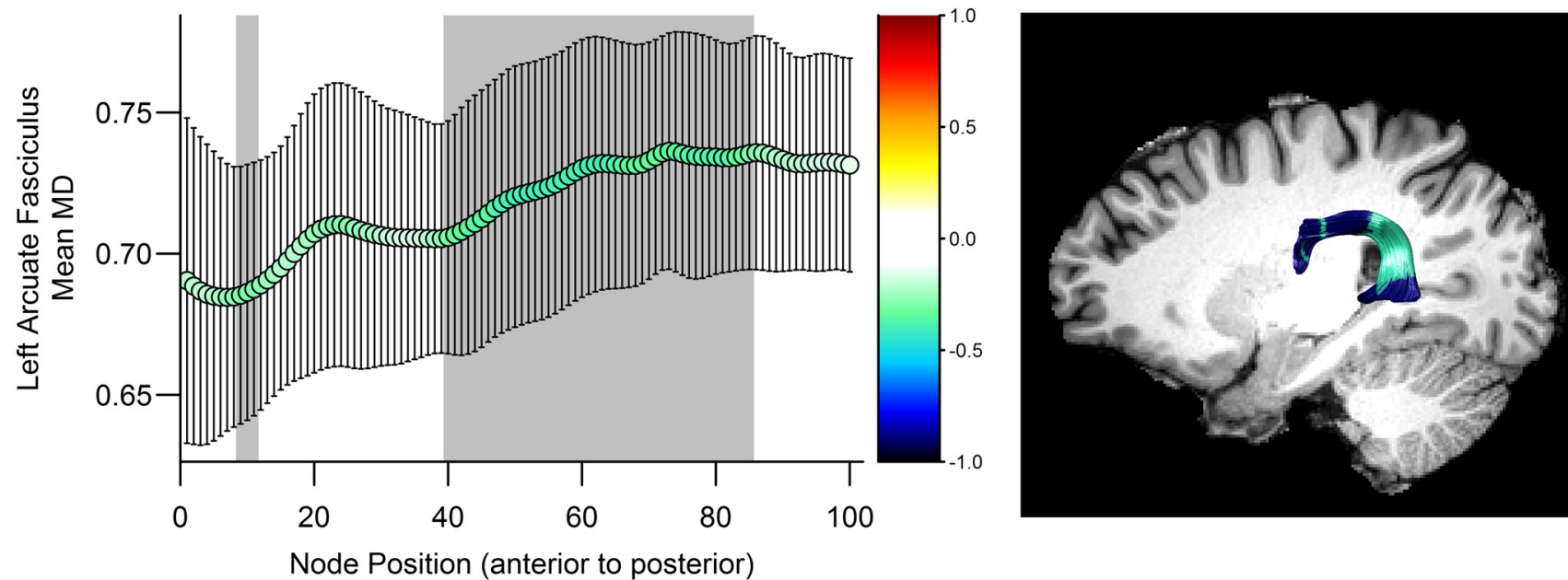

\section{Left FP SLF MD and Processing Speed}
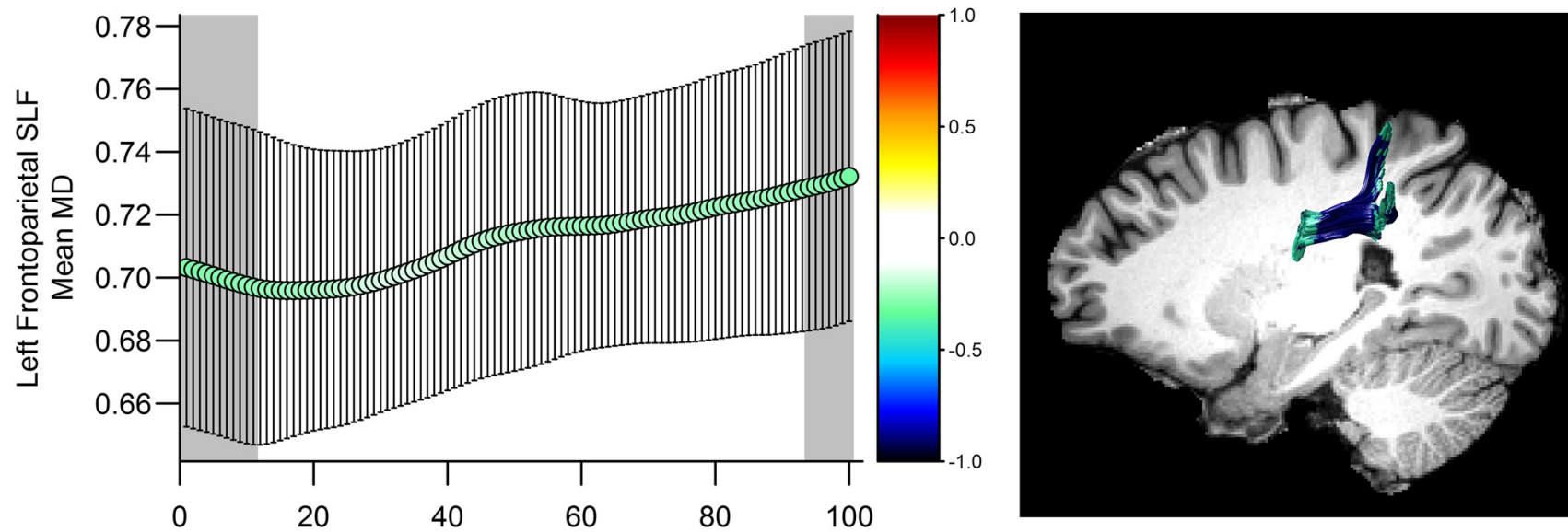

Node Position (anterior to posterior)

Figure 3. Correlations with diffusion metrics in the $(A, B)$ left arcuate fasciculus and ( $C$ left frontoparietal SLF by node position, and corresponding fiber renderings from an example participant. FPSLF, Frontoparietal superior longitudinal fasciculus. Color represents the $r$ value of the correlation at each node position. Shaded gray area represents nodes where the permutation-corrected significance level was $p<0.05$, which are depicted in color on the rendered fibers. $y$-axis indicates the mean value of the diffusion metric at each node represented by the $x$-axis. Error bars indicate SD of the mean diffusion metric. $A$, FA was significantly positively correlated with Vocabulary Knowledge in nodes $73-88$ of the left arcuate fasciculus. $B$, MD was significantly negatively correlated with processing speed in nodes $9-11$ and 40-85 of the left arcuate fasciculus. C, MD was significantly negatively correlated with processing speed in nodes 1-11 and 94-100 of the left frontoparietal SLF. The spread of the fibers at the posterior end of the tract is consistent with prior work (Catani et al., 2005). 
Table 2. Diffusion correlations with language and processing speed measures ${ }^{a}$

\begin{tabular}{lccc}
\hline & $\begin{array}{l}\text { Vocabulary } \\
\text { Knowledge }\end{array}$ & $\begin{array}{l}\text { Picture } \\
\text { Vocabulary }\end{array}$ & $\begin{array}{l}\text { Connections } \\
\text { Simple }\end{array}$ \\
\hline L arcuate fasciculus FA (nodes 73-88) & $0.38^{* * * b}$ & $0.31^{* *}$ & 0.16 \\
L arcuate fasciculus MD (nodes 40-85) & -0.18 & -0.14 & $-0.41^{* * * b}$ \\
R arcuate fasciculus MD (nodes 51-75) & -0.10 & -0.08 & $-0.44^{* * b}$ \\
L frontoparietal SLF MD (nodes 1-11) & -0.06 & -0.10 & $-0.28^{* * b}$ \\
R frontoparietal SLF MD (nodes 84-100) & -0.07 & -0.04 & $-0.31^{* * b}$ \\
\hline
\end{tabular}

${ }^{a}$ Correlations of diffusion metrics averaged across tract segments with Z-transformed scores on the cognitive metrics. L, Left; $R$, right. Bootstrap (1000) Cls for significant correlations: $L$ arcuate FA (nodes 73-88) with Vocabulary Knowledge $[0.17,0.55]$ and Picture Vocabulary $[0.12,0.48]$; L arcuate MD (nodes $40-85$ ) with Connections Simple $[-0.57,-0.23]$; and $R$ arcuate MD (nodes 51-75) with Connections Simple $[-0.60,-0.25]$.

${ }^{b}$ The nodes in the defined region exhibited significant correlations in permutation testing across the entire tract. ${ }^{* *} p<0.01$; ${ }^{* *} p<0.001$.

uted to the relation between MD and processing speed in the bilateral arcuate fasciculus and frontoparietal SLF.

\section{Local tract volume impacts arcuate fasciculus associations with vocabulary}

The results above indicate that FA associations with vocabulary were not dependent on age or age-related declines in T1w/T2w. Because FA is affected by many different white matter properties, we next investigated the hypothesis that these associations reflected differences in tract morphology (i.e., macrostructure) rather than microstructure per se. Arcuate fasciculus volume estimates across nodes 73-88 identified participants with high volume $(n=9)$, low volume $(n=7)$, or volume within the normal range. Thus, the 16 cases with extreme values were within the tails of a normal distribution of local arcuate fasciculus volume across participants. These cases exhibited small volume tracts with few fibers or large volume tracts with substantial flaring in the posterior segment of the tract where the FA-vocabulary relationship was significant (Fig. 2A). In contrast, cases with volume in the normal range exhibited relatively modest flaring as the fibers curved behind the Sylvian fissure (Fig. 2B). Intracranial volume did not differ between participants with normal compared with high arcuate fasciculus volume $\left(t_{(93)}=-0.71, p=0.48\right)$ but was significantly lower for participants with low arcuate volume than those with normal arcuate volume $\left(t_{(91)}=3.10, p<0.01\right.$; Table 4). Importantly, age did not differ across the volume groups $\left(F_{(2,99)}=1.20, p=0.30\right.$; Table 4$)$, indicating that arcuate fasciculus volume classification was independent of age.

Local arcuate fasciculus volume was related to Vocabulary Knowledge, as cases with volumes in the normal range exhibited significantly higher Vocabulary Knowledge compared with the high-volume $\left(t_{(93)}=2.28, p<0.05\right)$ and low-volume participants $\left(t_{(91)}=3.06, p<0.01\right.$; Table 4$)$. Removing high- and low-volume participants decreased the variance in Vocabulary Knowledge explained by FA in the left arcuate fasciculus by $5 \%$, although the correlation remained significant $(r=0.31, p<$ $0.05)$. These results suggest that the macrostructure of the arcuate fasciculus, rather than aging effects on tract microstructure, contribute to normative individual variability in vocabulary knowledge and may underlie its relative stability across the adult lifespan.

\section{Predicting vocabulary knowledge from demographic and neuroanatomical factors}

A multiple linear regression predicting Vocabulary Knowledge from gender, education, intracranial volume, and left arcuate fasciculus FA (nodes 73-88) was performed to assess the extent to which the arcuate fasciculus effects were inde- pendent of other developmental influences. Together, these variables explained $39 \%$ of the variance in Vocabulary Knowledge, although only education $(\beta=0.45, p<0.001)$ and left arcuate fasciculus FA $(\beta=0.28, p<0.01)$ were significant predictors (gender: $\beta=-0.13, p=0.18$; intracranial volume: $\beta=0.05, p=0.64$ ). Importantly, this result demonstrates that FA in the left arcuate fasciculus significantly predicts Vocabulary Knowledge, even after accounting for effects of gender, brain size, and education.

\section{Discussion}

Vocabulary knowledge was significantly associated with left arcuate fasciculus FA where the fibers pass by the supramarginal gyrus on their way to and from the temporal lobe. These effects were partially dependent on local tract volume and were not due to age despite evidence of age-related decline in $\mathrm{T} 1 \mathrm{w} / \mathrm{T} 2 \mathrm{w}$ across the arcuate fasciculus. In contrast, significant associations between processing speed and arcuate fasciculus microstructure were largely explained by aging effects. These results suggest that vocabulary knowledge is relatively preserved with age because it depends, at least in part, on the macrostructural development of the arcuate fasciculus.

\section{The role of the left arcuate fasciculus in vocabulary knowledge}

The arcuate fasciculus findings are consistent with considerable evidence linking left temporal-parietal white matter measures to the development and maintenance of normal language skills that include naming, verbal fluency, phonological decoding, and vocabulary (Klingberg et al., 2000; Deutsch et al., 2005; Wong et al., 2011). For instance, FA in lefthemisphere temporal-parietal white matter predicted the ability to name objects in pictures, after controlling for age, education, and total brain volume (Kucukboyaci et al., 2014). Similarly, we observed an FA association with vocabulary that was independent of age, education, gender, and total intracranial volume.

Inhomogeneous organization of arcuate fasciculus fibers or a relatively small number of fibers may underlie associations between FA and reading skills (Deutsch et al., 2005; Carter et al., 2009). Indeed, the qualitatively unique patterns of arcuate fasciculus morphology shown in Figure 2 and the results of the volume classification analysis support the premise that poor language abilities stem from atypical arcuate fasciculus patterning.

The cases with quite large arcuate volumes and extensive projections could reflect atypical pruning during development. Disrupted or incomplete synaptic pruning increases the number of neuronal connections but weakens their functional connectivity (Chung et al., 2013; Zhan et al., 2014), and is associated with abnormal enlargement of cortical and subcortical structures that predicts behavioral impairments (BeckelMitchener and Greenough, 2004; Hessl et al., 2004; Molnár and Kéri, 2014). The cases with quite small arcuate volumes could reflect extensive crossing fibers through the arcuate that limit the effectiveness of deterministic fiber tracking methods with 64 direction diffusion data. This idea may be supported by the RD association with vocabulary knowledge and could be due to an indirect posterior arcuate pathway that lies adjacent to and overlaps with the direct pathway examined in the current study (Catani et al., 2005; Catani and Thiebaut de Schotten, 2008; Budisavljevic et al., 2015; Weiner et al., 2016). Although spatial heterogeneity limited our ability to reliably 
A

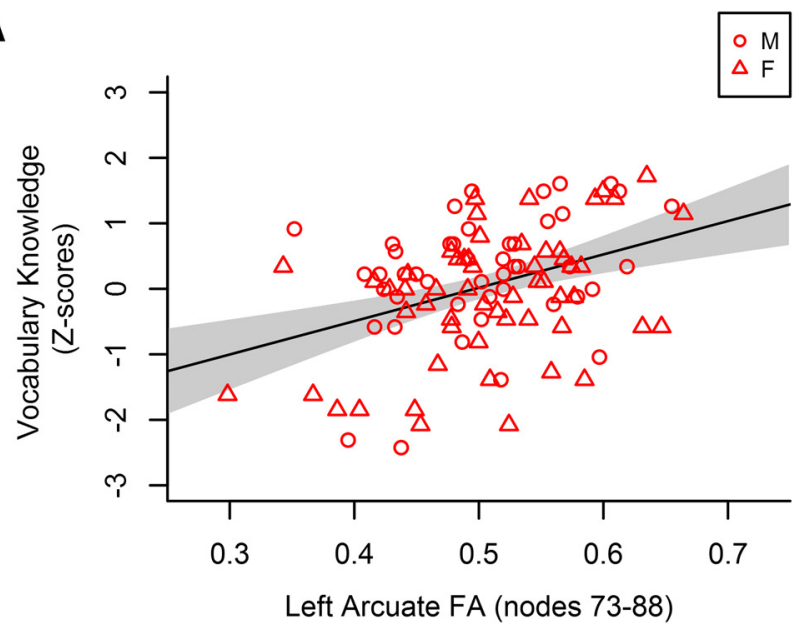

C

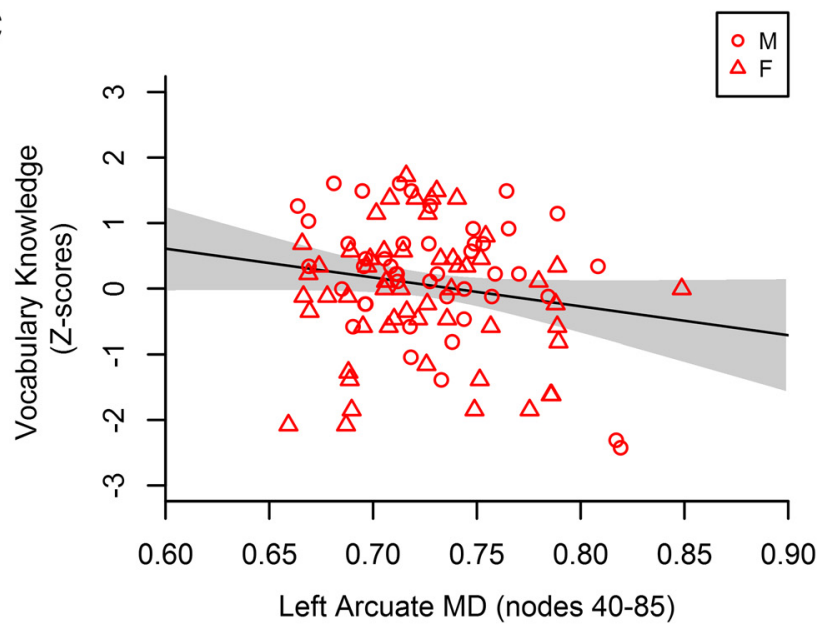

B

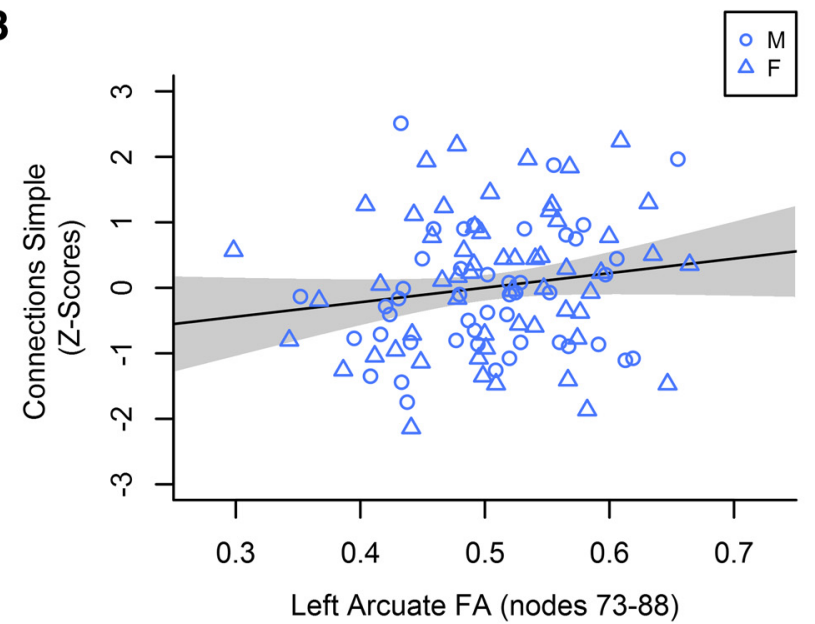

D

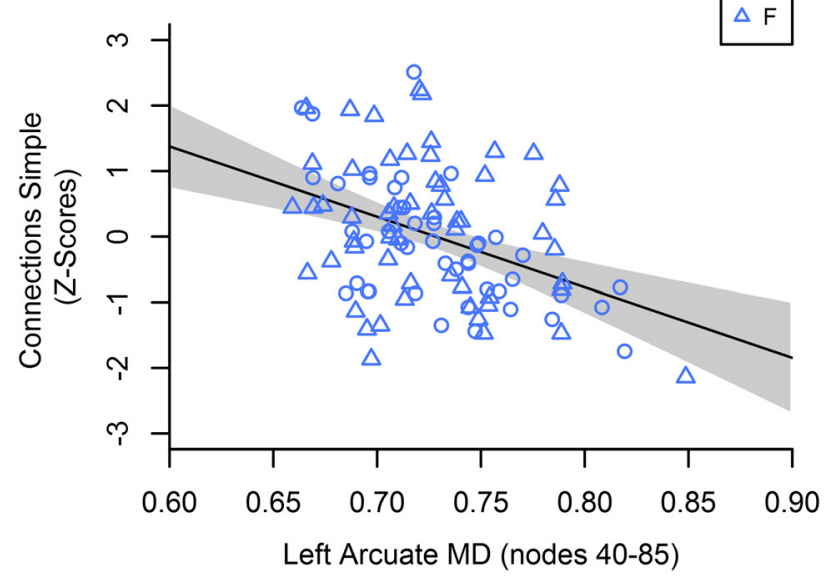

$\mathbf{E}$

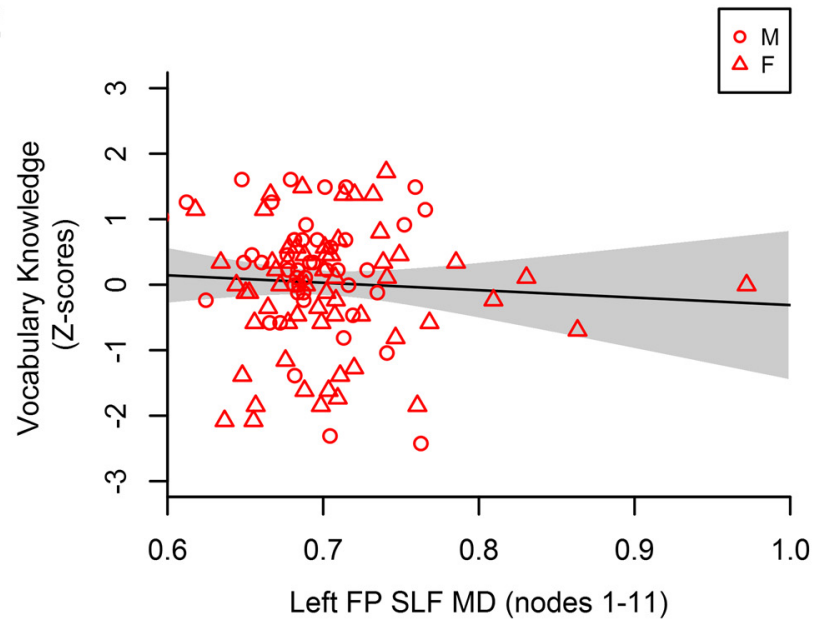

$\mathbf{F}$

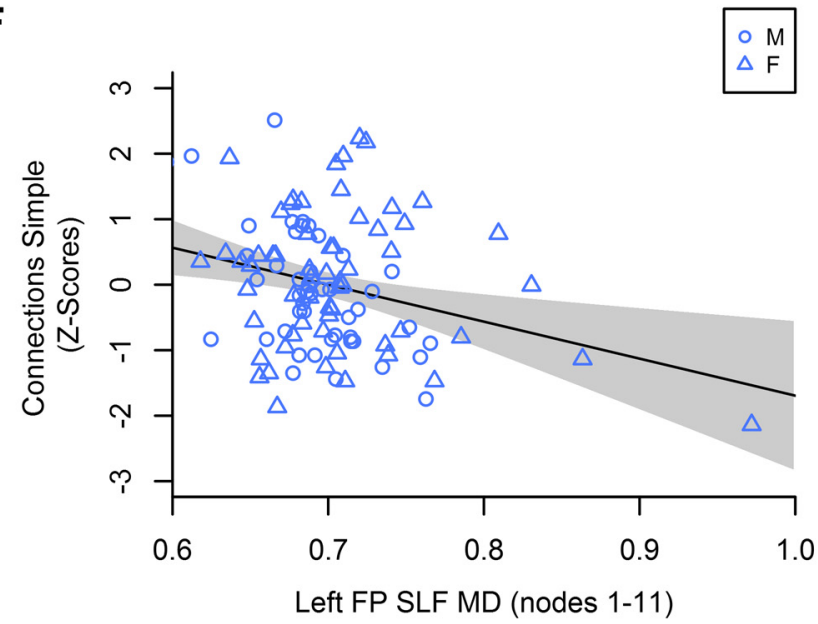

Figure 4. Correlations of diffusion metrics averaged across nodes in the arcuate fasciculus and frontoparietal SLF with vocabulary (red, left) and processing speed (blue, right). M, Male; F, female; FP SLF, frontoparietal superior longitudinal fasciculus. Gray shading represents the $95 \% \mathrm{Cl}$. Processing speed was measured by performance on the Connections Simple task such that higher values indicate faster processing. $A, \boldsymbol{B}$, Left arcuate fasciculus FA (nodes 73-88) was significantly positively correlated with Vocabulary Knowledge but not processing speed. $\boldsymbol{C}, \boldsymbol{D}$, Left arcuate fasciculus MD (nodes $40-85$ ) did not predict Vocabulary Knowledge but was significantly negatively correlated with processing speed. The correlation with processing speed in $\boldsymbol{D}$ was significantly stronger in males than females $(Z=-2.04, p<0.05$; males: $r=-0.61, p<0.001$; females: $r=-0.28, p<0.05$ ). $\boldsymbol{E}, \boldsymbol{F}$, Left frontoparietal SLF MD (nodes $1-11$ ) did not predict Vocabulary Knowledge but was significantly negatively correlated with processing speed. The correlation with processing speed in $\boldsymbol{F}$ was significantly stronger in males than females $(Z=-2.17, p<0.05 ;$ males: $r=$ $-0.57, p<0.001$; females: $r=-0.20, p=0.13$ ).

track these putative fibers, Vanderauwera et al. (2015) demonstrated an association between diffusion properties of the posterior arcuate fasciculus and a phonological processing measure, even when controlling for crossing fibers using spherical deconvolution. A simpler explanation, which is consistent with the observation of reduced intracranial volume, is that fewer arcuate fibers in these cases reflect fewer neuronal targets or impoverished lexical-semantic representations in 
Table 3. Correlations of age, the T1w/T2w ratio, and diffusion metrics in regions of interest $^{a}$

\begin{tabular}{|c|c|c|c|}
\hline & 1 & 2 & 3 \\
\hline \multicolumn{4}{|c|}{ L arcuate fasciculus (nodes $73-88$ ) } \\
\hline 1. Age & - & & \\
\hline 2. $\mathrm{T} 1 \mathrm{w} / \mathrm{T} 2 \mathrm{w}$ ratio & $-0.64^{* * *}$ & - & \\
\hline 3. FA & 0.05 & 0.02 & - \\
\hline \multicolumn{4}{|c|}{ L arcuate fasciculus (nodes $40-85$ ) } \\
\hline 1. Age & - & & \\
\hline 2. $\mathrm{T} 1 \mathrm{w} / \mathrm{T} 2 \mathrm{w}$ ratio & $-0.67^{* * *}$ & - & \\
\hline 3. MD & $0.38^{* * *}$ & $-0.45^{* * *}$ & - \\
\hline \multicolumn{4}{|c|}{ R arcuate fasciculus (nodes 51-75) } \\
\hline 1. Age & - & & \\
\hline 2. $\mathrm{T} 1 \mathrm{w} / \mathrm{T} 2 \mathrm{w}$ ratio & $-0.60^{* * *}$ & - & \\
\hline 3. MD & $0.32^{* *}$ & $-0.43^{* * *}$ & - \\
\hline \multicolumn{4}{|c|}{ L frontoparietal SLF (nodes 1-11) } \\
\hline 1. Age & - & & \\
\hline 2. $\mathrm{T} 1 \mathrm{w} / \mathrm{T} 2 \mathrm{w}$ ratio & $-0.69^{* * *}$ & - & \\
\hline 3. MD & $0.30^{* *}$ & $-0.39 * * *$ & - \\
\hline \multicolumn{4}{|c|}{ R frontoparietal SLF (nodes 84-100) } \\
\hline 1. Age & - & & \\
\hline 2. $\mathrm{T} 1 \mathrm{w} / \mathrm{T} 2 \mathrm{w}$ ratio & $-0.74^{* * *}$ & - & \\
\hline 3. MD & $0.29^{* *}$ & $-0.33^{* * *}$ & - \\
\hline
\end{tabular}

${ }^{a} \mathrm{~T} 1 \mathrm{w} / \mathrm{T} 2 \mathrm{w}$ ratio and diffusion metrics were averaged across the relevant nodes. $\mathrm{L}, \mathrm{Left} ; \mathrm{R}$, right.

${ }^{* *} p<0.01$; ${ }^{* * *} p<0.001$.

posterior middle temporal cortex (Lau et al., 2008) that could limit the complexity of combinatorial semantic operations in this region (Humphries et al., 2007). The results of the current study suggest that there is an optimal organization of arcuate fasciculus fibers for the acquisition and use of vocabulary knowledge that may be determined by the rate of arcuate fiber growth and pruning early in development (Yeatman et al., 2012a). This relationship may emerge selectively in an arcuate fasciculus region where fibers project toward targets that diverge in location across individuals, thus producing more variability in tract organization.

Arcuate fasciculus fibers appear to provide scaffolding for the development of reading skills that play an important role in the acquisition of new words. Four- to six-year-old prereading children with relatively elevated arcuate fasciculus volume and FA were better at combining sounds into words and decomposing words into sounds (Saygin et al., 2013). This FA association with phonological awareness was observed in a similar posterior distribution as the present study. In addition, correct recognition of recently learned sound sequences was associated with diffusion metrics in the left arcuate fasciculus (López-Barroso et al., 2013). These results suggest that optimal arcuate fasciculus organization provides for superior phonological awareness that translates into better reading fluency and facilitates the acquisition of vocabulary knowledge.

The left arcuate fasciculus findings may not simply reflect the accumulation of vocabulary knowledge. Glasser and Rilling (2008) proposed that the left arcuate fasciculus supports both a dorsal phonological-articulatory and a ventral lexical-semantic route of speech processing, with terminations in the superior and middle temporal gyri, respectively. The left posterior middle temporal gyrus/superior temporal sulcus in particular is thought to be involved in lexical storage (Lau et al., 2008), and cortical stimulation of this region disrupts retrieval of semantic knowledge (Corina et al., 2010). Optimal arcuate fasciculus structure may therefore support accurate retrieval of lexical-semantic information.
Despite consistent evidence that the left arcuate fasciculus supports a variety of reading and language skills, the present findings are among the first to directly link it to adult vocabulary knowledge. Madhavan et al. (2014) observed a significant association between left arcuate fasciculus FA and verbal fluency in healthy adults across the lifespan but found no association with receptive vocabulary. Importantly, both of the vocabulary measures in the current study characterize not only how much word knowledge a person has accumulated, but also the ability to retrieve and express that information. Additionally, the methods used in this study may have been sensitive to associations between left arcuate fasciculus and vocabulary because they (1) examined spatially specific effects along the course of the tract and (2) used core-weighted FA estimates to limit the impact of adjacent tracts that may have influenced findings in previous studies (Beaulieu et al., 2005; Deutsch et al., 2005; Niogi and McCandliss, 2006).

\section{Resilience of arcuate fasciculus associations with vocabulary knowledge to aging}

We observed evidence of typical age-related decline in T1w/ $\mathrm{T} 2 \mathrm{w}$ in middle to posterior segments of the arcuate fasciculus bilaterally, including the left posterior region where FA was associated with vocabulary knowledge regardless of age. Previous studies have described T1w/T2 $\mathrm{w}$ as an index of myelin within gray matter (Glasser and Van Essen, 2011; Grydeland et al., 2013; Ganzetti et al., 2014; Glasser et al., 2014), but it is unclear how it relates to myelin content in white matter (Sandrone et al., 2015). To the extent that T1w/T2w indexes myelin, loss of myelin may not be critical to the use of vocabulary knowledge in older adults, even though age-related changes in $\mathrm{T} 1 \mathrm{w} / \mathrm{T} 2 \mathrm{w}$ co-occur with declines in cognitive processing speed. While myelination is likely critical to the development of vocabulary knowledge (Wandell and Yeatman, 2013), our results suggest that the use of vocabulary in adulthood depends on other tissue properties known to affect FA. Such properties include the number of fibers, their orientation, and/or the coherence of their organization (Beaulieu, 2002; Mädler et al., 2008).

The local tract volume findings from this study have important implications for interpreting significant associations between FA and language abilities (e.g., reading skills, vocabulary knowledge) that are consistently observed in left temporal-parietal white matter. These associations are often attributed to individual differences in tract microstructure (Klingberg et al., 2000), which is a reasonable interpretation given that FA can be influenced by myelin content and fiber density and may be critical in development. Our results suggest that macrostructure also affects FA in this region of the arcuate fasciculus where fibers begin to flare outward as they project to different terminations in the temporal lobe (Fig. 2).

Thus, vocabulary knowledge may be relatively unaffected by age-related declines and is more strongly determined by developmental differences in arcuate fasciculus organization that affect the acquisition and expression of vocabulary knowledge across the adult lifespan. FA effects were specific to the left temporal-parietal arcuate fasciculus branch and remained significant after controlling for intracranial volume, suggesting that the organization of the left posterior arcuate fasciculus in particular is important for the expression of vocabulary knowledge. Normal variation in left arcuate morphology may limit the potential impact of age-related white matter declines on vocabulary knowledge, suggesting that large longitudinal studies are necessary to detect any effects of 
A

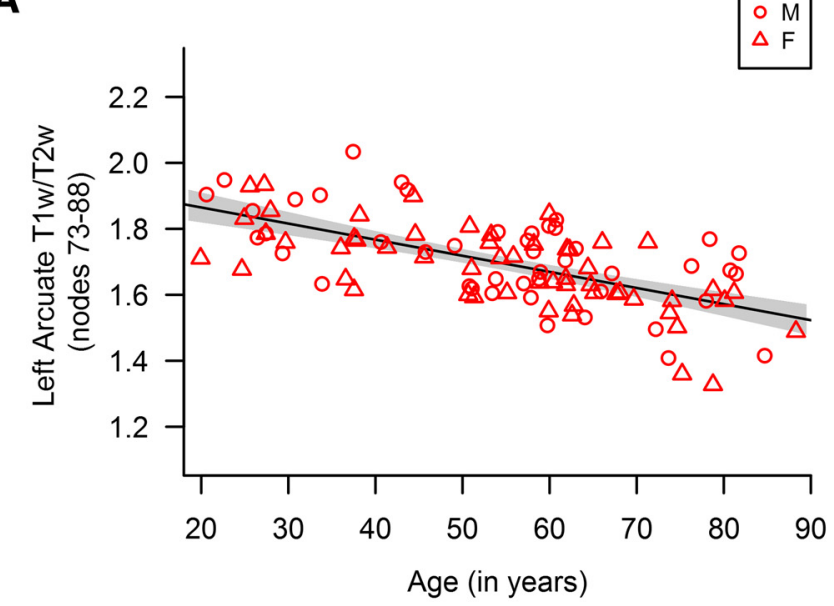

C

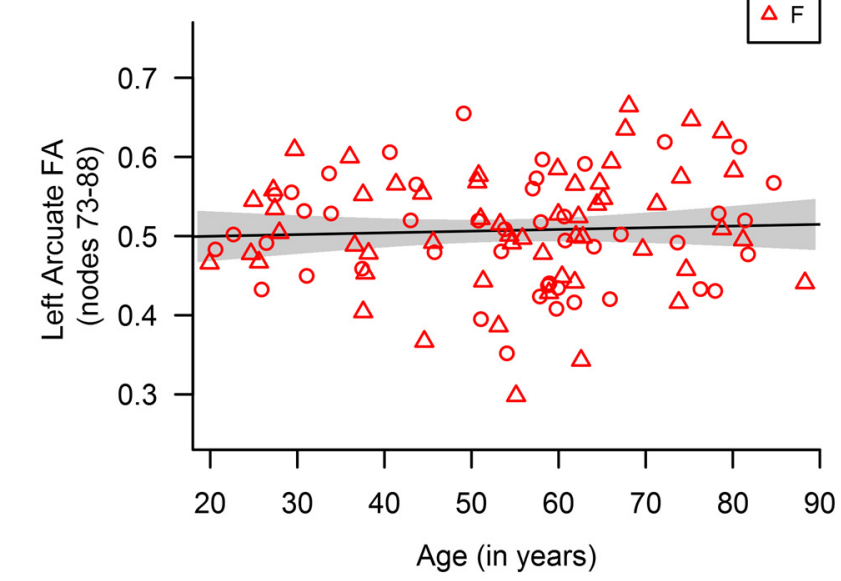

$\mathbf{E}$

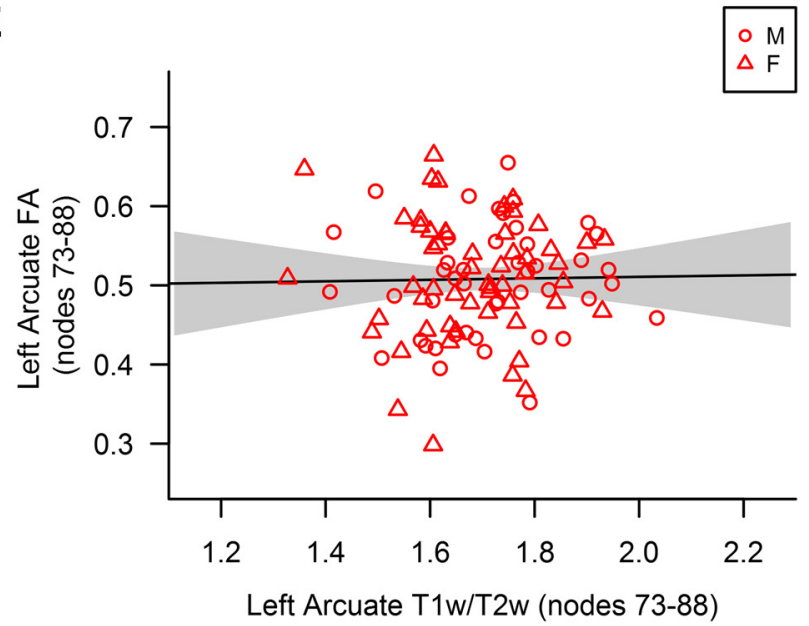

B

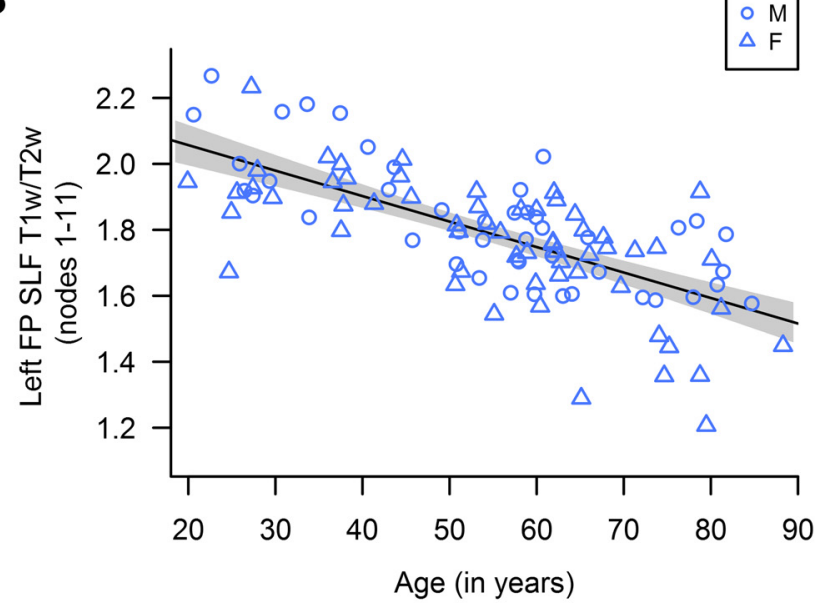

D

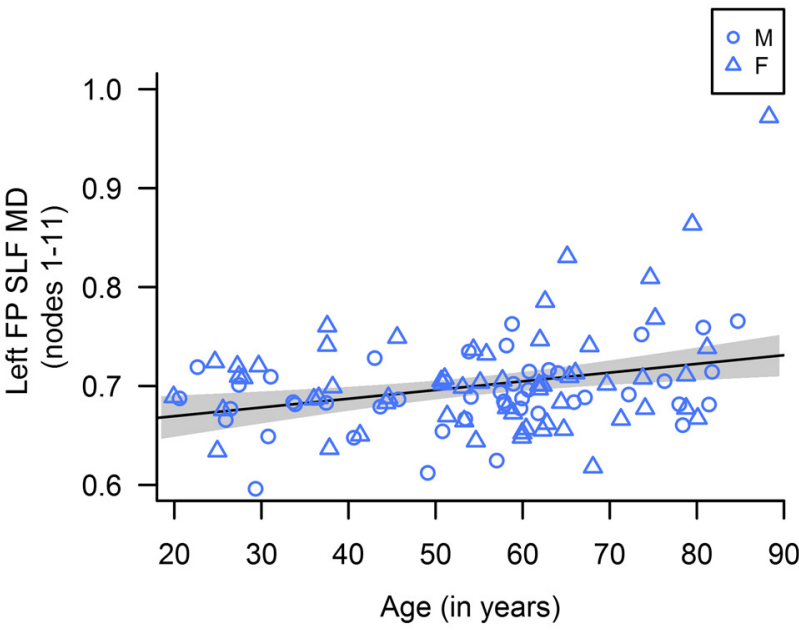

F
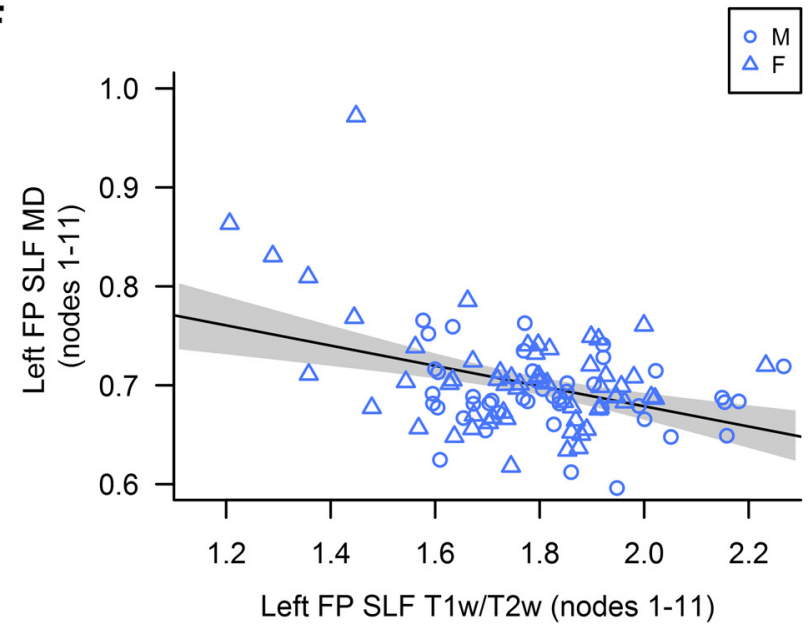

Figure 5. Correlations between age, T1w/T2w, and diffusion metrics averaged across nodes in the arcuate fasciculus and frontoparietal SLF. M, Male; F, female; FP SLF, frontoparietal superior longitudinal fasciculus. Gray shading represents $95 \% \mathrm{Cl}$. $\boldsymbol{A}, \boldsymbol{B}$, Age was significantly negatively correlated with T1w/T2w in both the left arcuate (nodes $73-88$ ) and left frontoparietal SLF (1-11). $\boldsymbol{C}, \boldsymbol{D}$, Age was not correlated with FA in the left arcuate (nodes 73-88) but was significantly positively correlated with MD in the left frontoparietal SLF (nodes $1-11$ ). $\boldsymbol{E}, \boldsymbol{F}, \mathrm{T} 1$ w/T2w was not correlated with FA in the left arcuate (nodes 73-88) but was significantly positively correlated with MD in the left frontoparietal SLF (nodes 1-11).

pronounced age-related white matter declines on vocabulary knowledge.

In conclusion, the structural organization of the left posterior arcuate fasciculus explains unique variance in vocabulary knowledge in adults. The arcuate fasciculus effect was resilient to age-related declines in a T1w/T2w myelin-enhanced contrast but was associated with extreme posterior tract volume, suggesting that it reflects stable individual differences in tract morphology. Thus, developmental patterning of arcuate fasciculus projections appears to be important for the expression of vocabulary knowledge that is resilient to the widespread effects of aging on white matter microstructure. Considering the developmental profiles that give rise to variability in left arcuate fasciculus morphology may help delineate the neural 


\begin{tabular}{|c|c|c|c|}
\hline & Normal & High Volume & Low Volume \\
\hline Vocabulary Knowledge $^{a}$ & $64.70(7.67)$ & $58.44(9.25)^{*}$ & $55.43(8.22)^{*}$ \\
\hline FA & $0.51(0.07)$ & $0.48(0.05)$ & $0.45(0.06)^{*}$ \\
\hline Intracranial volume & $1492.72(185.58)$ & $1538.73(176.69)$ & $1271.57(112.15)^{* *}$ \\
\hline Age & $55.24(16.55)$ & $51.32(22.45)$ & $45.38(18.17)$ \\
\hline
\end{tabular}

${ }^{a}$ Vocabulary Knowledge is reported as raw scores.

${ }^{*} p<0.05$; ${ }^{* *} p<0.01$; difference from normal group.

mechanisms underlying individual differences in language abilities across the lifespan.

\section{References}

Arbuckle TY, Maag U, Pushkar D, Chaikelson JS (1998) Individual differences in trajectory of intellectual development over 45 years of adulthood. Psychol Aging 13:663-675. CrossRef Medline

Ashburner J, Friston KJ (2005) Unified segmentation. Neuroimage 26: 839-851. CrossRef Medline

Basser PJ, Pajevic S, Pierpaoli C, Duda J, Aldroubi A (2000) In vivo fiber tractography using dt-MRI data. Magn Reson Med 44:625-632. CrossRef Medline

Beaulieu C (2002) The basis of anisotropic water diffusion in the nervous system: a technical review. NMR Biomed 15:435-455. CrossRef Medline

Beaulieu C, Plewes C, Paulson LA, Roy D, Snook L, Concha L, Phillips L (2005) Imaging brain connectivity in children with diverse reading ability. Neuroimage 25:1266-1271. CrossRef Medline

Beckel-Mitchener A, Greenough WT (2004) Correlates across the structural, functional, and molecular phenotypes of fragile X syndrome. Ment Retard Dev Disabil Res Rev 10:53-59. CrossRef Medline

Behrens TE, Woolrich MW, Jenkinson M, Johansen-Berg H, Nunes RG, Clare S, Matthews PM, Brady JM, Smith SM (2003) Characterization and propagation of uncertainty in diffusion-weighted MR imaging. Magn Reson Med 50:1077-1088. CrossRef Medline

Bennett IJ, Madden DJ, Vaidya CJ, Howard DV, Howard JH Jr (2010) Agerelated differences in multiple measures of white matter integrity: a diffusion tensor imaging study of healthy aging. Hum Brain Mapp 31: 378-390. CrossRef Medline

Borella E, Carretti B, De Beni R (2008) Working memory and inhibition across the adult life-span. Acta Psychol (Amst) 128:33-44. CrossRef Medline

Borella E, Ludwig C, Dirk J, de Ribaupierre A (2011) The influence of time of testing on interference, working memory, processing speed, and vocabulary: age differences in adulthood. Exp Aging Res 37:76-107. CrossRef Medline

Budisavljevic S, Dell'Acqua F, Rijsdijk FV, Kane F, Picchioni M, McGuire P, Toulopoulou T, Georgiades A, Kalidindi S, Kravariti E, Murray RM, Murphy DG, Craig MC, Catani M (2015) Age-related differences and heritability of the perisylvian language networks. J Neurosci 35:12625-12634. CrossRef Medline

Burzynska AZ, Preuschhof C, Bäckman L, Nyberg L, Li SC, Lindenberger U, Heekeren HR (2010) Age-related differences in white matter microstructure: region-specific patterns of diffusivity. Neuroimage 49:21042112. CrossRef Medline

Carlisle JF (2000) Awareness of the structure and meaning of morphologically complex words: impact on reading. Reading Writing 12:169-190. CrossRef

Carter JC, Lanham DC, Cutting LE, Clements-Stephens AM, Chen X, Hadzipasic M, Kim J, Denckla MB, Kaufmann WE (2009) A dual DTI approach to analyzing white matter in children with dyslexia. Psychiatry Res 172:215-219. CrossRef Medline

Catani M, Thiebaut de Schotten M (2008) A diffusion tensor imaging tractography atlas for virtual in vivo dissections. Cortex 44:1105-1132. CrossRef Medline

Catani M, Jones DK, ffytche DH (2005) Perisylvian language networks of the human brain. Ann Neurol 57:8-16. CrossRef Medline

Chung WS, Clarke LE, Wang GX, Stafford BK, Sher A, Chakraborty C, Joung J, Foo LC, Thompson A, Chen C, Smith SJ, Barres BA (2013) Astrocytes mediate synapse elimination through MEGF10 and MERTK pathways. Nature 504:394-400. CrossRef Medline
Corina DP, Loudermilk BC, Detwiler L, Martin RF, Brinkley JF, Ojemann G (2010) Analysis of naming errors during cortical stimulation mapping: implications for models of language representation. Brain Lang 115: 101-112. CrossRef Medline

Cunningham AE, Stanovich KE (1997) Early reading acquisition and its relation to reading experience and ability 10 years later. Dev Psychol 33: 934-945. CrossRef Medline

Deutsch GK, Dougherty RF, Bammer R, Siok WT, Gabrieli JD, Wandell B (2005) Children's reading performance is correlated with white matter structure measured by diffusion tensor imaging. Cortex 41:354-363. CrossRef Medline

Eckert MA (2011) Slowing down: age-related neurobiological predictors of processing speed. Front Neurosci 5:25. CrossRef Medline

Feldman HM, Lee ES, Yeatman JD, Yeom KW (2012) Language and reading skills in school-aged children and adolescents born preterm are associated with white matter properties on diffusion tensor imaging. Neuropsychologia 50:3348-3362. CrossRef Medline

Fjell AM, Westlye LT, Amlien IK, Walhovd KB (2012) A multi-modal investigation of behavioral adjustment: Post-error slowing is associated with white matter characteristics. Neuroimage 61:195-205. CrossRef Medline

Frye RE, Liederman J, Hasan KM, Lincoln A, Malmberg B, McLean J 3rd, Papanicolaou A (2011) Diffusion tensor quantification of the relations between microstructural and macrostructural indices of white matter and reading. Hum Brain Mapp 32:1220-1235. CrossRef Medline

Ganzetti M, Wenderoth N, Mantini D (2014) Whole brain myelin mapping using T1- and T2-weighted MR imaging data. Front Hum Neurosci 8:671. CrossRef Medline

Glasser MF, Rilling JK (2008) DTI tractography of the human brain's language pathways. Cereb Cortex 18:2471-2482. CrossRef Medline

Glasser MF, Van Essen DC (2011) Mapping human cortical areas in vivo based on myelin content as revealed by T1- and T2-weighted MRI. J Neurosci 31:11597-11616. CrossRef Medline

Glasser MF, Goyal MS, Preuss TM, Raichle ME, Van Essen DC (2014) Trends and properties of human cerebral cortex: correlations with cortical myelin content. Neuroimage 93:165-175. CrossRef Medline

Grydeland H, Walhovd KB, Tamnes CK, Westlye LT, Fjell AM (2013) Intracortical myelin links with performance variability across the human lifespan: results from T1- and T2-weighted MRI myelin mapping and diffusion tensor imaging. J Neurosci 33:18618-18630. CrossRef Medline

Hermundstad AM, Bassett DS, Brown KS, Aminoff EM, Clewett D, Freeman S, Frithsen A, Johnson A, Tipper CM, Miller MB, Grafton ST, Carlson JM (2013) Structural foundations of resting-state and task-based functional connectivity in the human brain. Proc Natl Acad Sci U S A 110:6169_ 6174. CrossRef Medline

Hessl D, Rivera SM, Reiss AL (2004) The neuroanatomy and neuroendocrinology of fragile X syndrome. Ment Retard Dev Disabil Res Rev 10:17-24. CrossRef Medline

Hoeft F, McCandliss BD, Black JM, Gantman A, Zakerani N, Hulme C, Lyytinen H, Whitfield-Gabrieli S, Glover GH, Reiss AL, Gabrieli JD (2011) Neural systems predicting long-term outcome in dyslexia. Proc Natl Acad Sci U S A 108:361-366. CrossRef Medline

Humphries C, Binder JR, Medler DA, Liebenthal E (2007) Time course of semantic processes during sentence comprehension: an fMRI study. Neuroimage 36:924-932. CrossRef Medline

Johnson RT, Yeatman JD, Wandell BA, Buonocore MH, Amaral DG, Nordahl CW (2013) Diffusion properties of major white matter tracts in young, typically developing children. Neuroimage 88:143-154. CrossRef Medline

Jones DK, Knösche TR, Turner R (2013) White matter integrity, fiber count, and other fallacies: the do's and don'ts of diffusion MRI. Neuroimage 73:239-254. CrossRef Medline

Kennedy KM, Raz N (2009) Aging white matter and cognition: differential effects of regional variations in diffusion properties on memory, executive functions, and speed. Neuropsychologia 47:916-927. CrossRef Medline

Klingberg T, Hedehus M, Temple E, Salz T, Gabrieli JD, Moseley ME, Poldrack RA (2000) Microstructure of temporo-parietal white matter as a basis for reading ability: evidence from diffusion tensor magnetic resonance imaging. Neuron 25:493-500. CrossRef Medline

Kucukboyaci NE, Kemmotsu N, Leyden KM, Girard HM, Tecoma ES, Iragui VJ, McDonald CR (2014) Integration of multimodal MRI data via PCA to explain language performance. Neuroimage Clin 5:197-207. CrossRef Medline 
Lau EF, Phillips C, Poeppel D (2008) A cortical network for semantics: (de)constructing the N400. Nat Rev Neurosci 9:920-933. CrossRef Medline

Lebel C, Gee M, Camicioli R, Wieler M, Martin W, Beaulieu C (2012) Diffusion tensor imaging of white matter tract evolution over the lifespan. Neuroimage 60:340-352. CrossRef Medline

Lonigan CJ, Anthony JL, Phillips BM, Purpura DJ, Wilson SB, McQueen JD (2009) The nature of preschool phonological processing abilities and their relations to vocabulary, general cognitive abilities, and print knowledge. J Educ Psychol 101:345-358. CrossRef Medline

López-Barroso D, Catani M, Ripollés P, Dell’Acqua F, Rodríguez-Fornells A, de Diego-Balaguer R (2013) Word learning is mediated by the left arcuate fasciculus. Proc Natl Acad Sci U S A 110:13168-13173. CrossRef Medline

Madhavan KM, McQueeny T, Howe SR, Shear P, Szaflarski J (2014) Superior longitudinal fasciculus and language functioning in healthy aging. Brain Res 1562:11-22. CrossRef Medline

Mädler B, Drabycz SA, Kolind SH, Whittall KP, MacKay AL (2008) Is diffusion anisotropy an accurate monitor of myelination? Correlation of multicomponent $\mathrm{T} 2$ relaxation and diffusion tensor anisotropy in human brain. Magn Reson Imaging 26:874-888. CrossRef Medline

Molnár K, Kéri S (2014) Bigger is better and worse: on the intricate relationship between hippocampal size and memory. Neuropsychologia 56: 73-78. CrossRef Medline

Mori S, Oishi K, Jiang H, Jiang L, Li X, Akhter K, Hua K, Faria AV, Mahmood A, Woods R, Toga AW, Pike GB, Neto PR, Evans A, Zhang J, Huang H, Miller MI, van Zijl P, Mazziotta J (2008) Stereotaxic white matter atlas based on diffusion tensor imaging in an ICBM template. Neuroimage 40:570-582. CrossRef Medline

Mugler JP 3rd, Brookeman JR (1990) Three-dimensional magnetizationprepared rapid gradient-echo imaging (3D MP RAGE). Magn Reson Med 15:152-157. CrossRef Medline

Nagy WE, Anderson RC (1984) How many words are there in printed school English? Reading Res Q 19:304-330. CrossRef

Nichols TE, Holmes AP (2002) Nonparametric permutation tests for functional neuroimaging: a primer with examples. Hum Brain Mapp 15:1-25. CrossRef Medline

Niogi SN, McCandliss BD (2006) Left lateralized white matter microstructure accounts for individual differences in reading ability and disability. Neuropsychologia 44:2178-2188. CrossRef Medline

Ocklenburg S, Schlaffke L, Hugdahl K, Westerhausen R (2014) From structure to function in the lateralized brain: how structural properties of the arcuate and uncinate fasciculus are associated with dichotic listening performance. Neurosci Lett 580:32-36. CrossRef Medline

Osher DE, Saxe RR, Koldewyn K, Gabrieli JD, Kanwisher N, Saygin ZM (2016) Structural connectivity fingerprints predict cortical selectivity for multiple visual categories across cortex. Cereb Cortex 26:1668-1683. CrossRef Medline

Pajevic S, Basser PJ, Fields RD (2014) Role of myelin plasticity in oscillations and synchrony of neuronal activity. Neuroscience 276:135-147. CrossRef Medline

Park DC, Smith AD, Lautenschlager G, Earles JL, Frieske D, Zwahr M, Gaines CL (1996) Mediators of long-term memory performance across the life span. Psychol Aging 11:621-637. CrossRef Medline

Park DC, Lautenschlager G, Hedden T, Davidson NS, Smith AD, Smith PK (2002) Models of visuospatial and verbal memory across the adult life span. Psychol Aging 17:299-320. CrossRef Medline

Persad CC, Abeles N, Zacks RT, Denburg NL (2002) Inhibitory changes after age 60 and their relationship to measures of attention and memory. J Gerontol B Psychol Sci Soc Sci 57:P223-P232. CrossRef Medline

Rimrodt SL, Peterson DJ, Denckla MB, Kaufmann WE, Cutting LE (2010) White matter microstructural differences linked to left perisylvian language network in children with dyslexia. Cortex 46:739-749. CrossRef Medline

Sala S, Agosta F, Pagani E, Copetti M, Comi G, Filippi M (2012) Microstructural changes and atrophy in brain white matter tracts with aging. Neurobiol Aging 33:488-498.e2. CrossRef Medline

Salthouse TA (1991) Mediation of adult age differences in cognition by reductions in working memory and speed of processing. Psychol Sci 2: 179-183. CrossRef

Salthouse TA, Toth J, Daniels K, Parks C, Pak R, Wolbrette M, Hocking KJ
(2000) Effects of aging on efficiency of task switching in a variant of the trail making test. Neuropsychology 14:102-111. CrossRef Medline

Sandrone S, Thiebaut de Schotten M, Reimann K, Murphy D, Geyer S, Catani M, Dell'Acqua F (2015) T1-weighted/T2-weighted MRI myelin mapping does not map myelin in the human corpus callosum. In: Organization for Human Brain Mapping. Honolulu.

Saygin ZM, Osher DE, Koldewyn K, Reynolds G, Gabrieli JD, Saxe RR (2012) Anatomical connectivity patterns predict face selectivity in the fusiform gyrus. Nat Neurosci 15:321-327. CrossRef Medline

Saygin ZM, Norton ES, Osher DE, Beach SD, Cyr AB, Ozernov-Palchik O, Yendiki A, Fischl B, Gaab N, Gabrieli JD (2013) Tracking the roots of reading ability: white matter volume and integrity correlate with phonological awareness in prereading and early-reading kindergarten children. J Neurosci 33:13251-13258. CrossRef Medline

Schaie KW, Willis SL (1993) Age difference patterns of psychometric intelligence in adulthood: generalizability within and across ability domains. Psychol Aging 8:44-55. CrossRef Medline

Schmierer K, Wheeler-Kingshott CA, Tozer DJ, Boulby PA, Parkes HG, Yousry TA, Scaravilli F, Barker GJ, Tofts PS, Miller DH (2008) Quantitative magnetic resonance of postmortem multiple sclerosis brain before and after fixation. Magn Reson Med 59:268 -277. CrossRef Medline

Schroeder DH, Salthouse TA (2004) Age-related effects on cognition between 20 and 50 years of age. Pers Individual Diff 36:393-404. CrossRef

Vanderauwera J, Vandermosten M, Dell'Acqua F, Wouters J, Ghesquière P (2015) Disentangling the relation between left temporoparietal white matter and reading: a spherical deconvolution tractography study. Hum Brain Mapp 36:3273-3287. CrossRef Medline

Vandermosten M, Boets B, Poelmans H, Sunaert S, Wouters J, Ghesquière P (2012) A tractography study in dyslexia: neuroanatomic correlates of orthographic, phonological and speech processing. Brain 135:935-948. CrossRef Medline

Voineskos AN, Rajji TK, Lobaugh NJ, Miranda D, Shenton ME, Kennedy JL, Pollock BG, Mulsant BH (2012) Age-related decline in white matter tract integrity and cognitive performance: a DTI tractography and structural equation modeling study. Neurobiol Aging 33:21-34. CrossRef Medline

Wandell BA, Yeatman JD (2013) Biological development of reading circuits. Curr Opin Neurobiol 23:261-268. CrossRef Medline

Wechsler D (1999) Wechsler abbreviated scale of intelligence. San Diego: Psychological Corporation.

Weiner KS, Yeatman JD, Wandell BA (2016) The posterior arcuate fasciculus and the vertical occipital fasciculus. Cortex Cortex. Advance online publication. Retrieved Mar. 31, 2016. doi: 10.1016/j.cortex.2016.03.012. CrossRef Medline

Wong FC, Chandrasekaran B, Garibaldi K, Wong PC (2011) White matter anisotropy in the ventral language pathway predicts sound-to-word learning success. J Neurosci 31:8780-8785. CrossRef Medline

Woodcock RW, McGrew KS, Mather N (2001) Woodcock-Johnson III. Itasca: Riverside.

Yeatman JD, Dougherty RF, Rykhlevskaia E, Sherbondy AJ, Deutsch GK, Wandell BA, Ben-Shachar M (2011) Anatomical properties of the arcuate fasciculus predict phonological and reading skills in children. J Cogn Neurosci 23:3304-3317. CrossRef Medline

Yeatman JD, Dougherty RF, Ben-Shachar M, Wandell BA (2012a) Development of white matter and reading skills. Proc Natl Acad Sci U S A 109: E3045-E3053. CrossRef Medline

Yeatman JD, Dougherty RF, Myall NJ, Wandell BA, Feldman HM (2012b) Tract profiles of white matter properties: automating fiber-tract quantification. PLoS One 7:e49790. CrossRef Medline

Yeatman JD, Wandell BA, Mezer AA (2014) Lifespan maturation and degeneration of human brain white matter. Nat Commun 5:4932. CrossRef Medline

Zhan Y, Paolicelli RC, Sforazzini F, Weinhard L, Bolasco G, Pagani F, Vyssotski AL, Bifone A, Gozzi A, Ragozzino D, Gross CT (2014) Deficient neuron-microglia signaling results in impaired functional brain connectivity and social behavior. Nat Neurosci 17:400-406. CrossRef Medline

Zhang Y, Du AT, Hayasaka S, Jahng GH, Hlavin J, Zhan W, Weiner MW, Schuff N (2010) Patterns of age-related water diffusion changes in human brain by concordance and discordance analysis. Neurobiol Aging 31:1991-2001. CrossRef Medline 